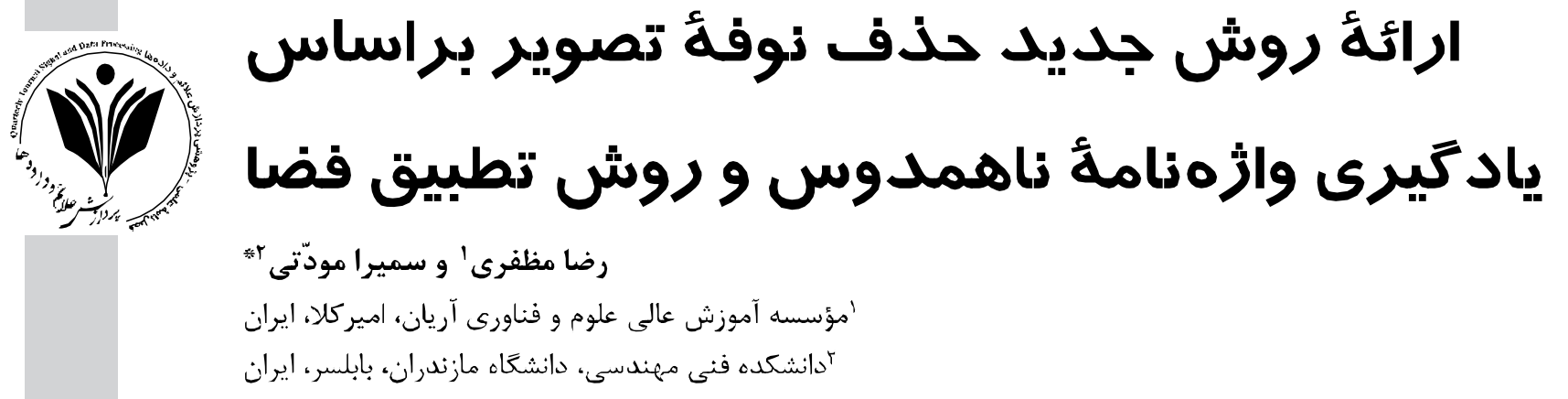

جكيده

در اين مقاله يك روش جديد بهمنظور حذف نوفه تصوير براساس يادكيرى وازهناهه ناهمدوس در فضاى تطبيق يافته ارائه مى شود. روال

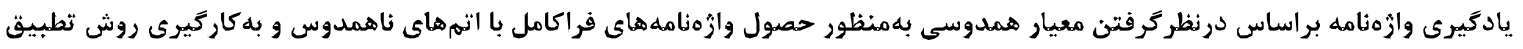

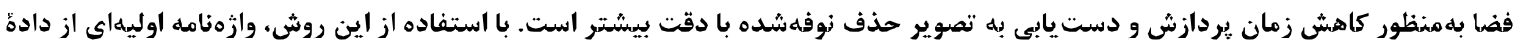

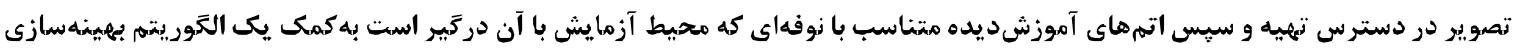

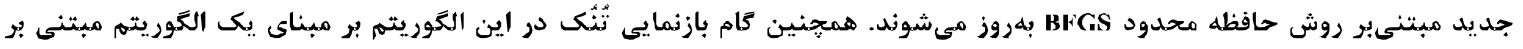

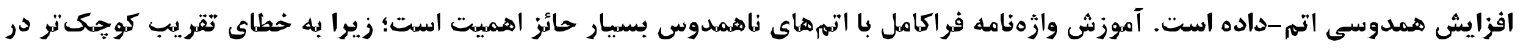

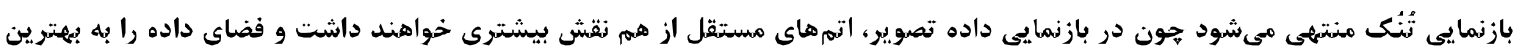

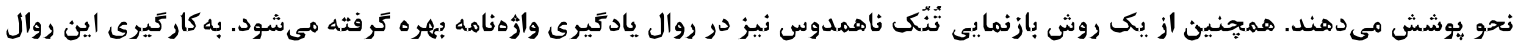

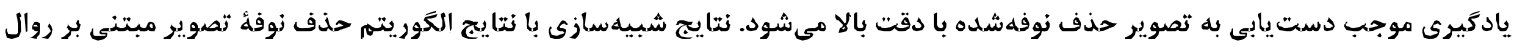

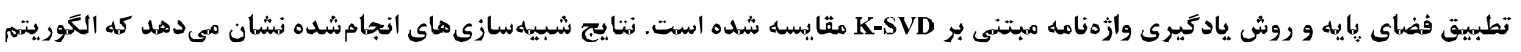

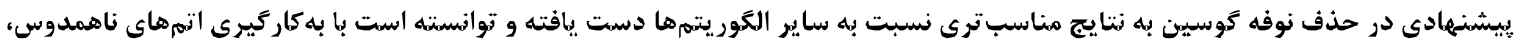

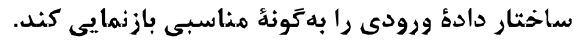

واز5ان كليدى: حذف نوفه، بروازش تصوير، ياد ئيرى وازمنامه، همدوسى، تطبيق فضا

\title{
A Novel Image Denoising Method Based on Incoherent Dictionary Learning and Domain Adaptation Technique
}

\author{
Reza Mozafari ${ }^{1}$ \& Samira Mavaddati ${ }^{2 *}$ \\ ${ }^{1}$ Master of Science in Electronic Enginecring, Aryan Institute of Iligher Education and \\ Technology, Amirkola, Iran \\ ${ }^{2}$ Electrical Department, Faculty of Technology and Engineering, University of Mazandaran, \\ Babolsar, Iran
}

\begin{abstract}
In this paper, a new method for image denoising based on incoherent dictionary learning and domain transfer technique is proposed. The idea of using sparse representation concept is one of the most interesting areas for researchers. The goal of sparse coding is to approximately model the input data as a weighted linear combination of a small number of basis vectors. Two characteristics should be considered in the dictionary learning process: Atom-data coherence and mutual coherence between dictionary atoms. The first one

* Corresponding author

* *ويسنده عرهددار مكاتبات

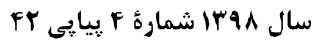

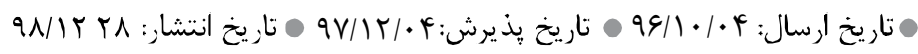


determines the dependency between the dictionary atoms and training data frames. This criterion value should be high. Another parameter expresses the dependency between atoms defined as the maximum absolute value of the cross-correlations between them. Higher coherence to the data class and lower mutual coherence between atoms result in a small approximation error in sparse coding procedure. In the proposed dictionary learning process, a coherence criterion is employed to yield over complete dictionaries with the incoherent atoms. The purpose of learning dictionary with low mutual coherence value is to reduce the approximation error of sparse representation in the denoising process and also decrease the computing time. We utilize the least angle regression with coherence eriterion (LARC) algorithm for sparse representation based on atom-data coherence in the first step of dictionary learning process. LARC sparse coding is an optimized gencralization of the least angle regression algorithm with stopping condition based on a residual coherence. This approach is based on setting a variable cardinality value.

Using atom-data coherence measure as stopping criteria in the sparse coding process yields the capability of balancing between source confusion and source distortion. A high value for the cardinality parameter or too dense coding results in the source confusion since the number of dictionary atoms is more than what is required for a proper representation. Source degradation oceurs when the sparse coding is done with low cardinality parameter or too sparse coding. Therefore, the number of required atoms will not be enough and data cannot be coded exactly over these atoms. Therefore, the setting procedure of cardinality parameter must be performed precisely.

The problem of finding a dictionary with low mutual coherence between its normalized atoms can be obtained by considering the Gram matrix. The mutual coherence is described by the maximum absolute value of the off-diagonal elements of this matrix. If all off-diagonal elements are the same, a dictionary with minimum self-coherence value is obtained.

Also, we take advantage of domain adaptation technique to transfer a learned dictionary to an adapted dictionary in the denoising process. The initial atoms set randomly and are updated based on the selected patches of input noisy image using the proposed alternating optimization algorithm.

According to these issues, the fitness function in dictionary learning problem includes three main sections: The first term is related to the minimization of approximation error. The next items are the incoherence criterion of dictionary atoms. The last one includes a transformation of initial atoms according to some patches of the noisy input data in the test step. We use limited-memory BFGS algorithm as an iterative solution for regular minimization of our objective function involved different terms. The simulation results show that the proposed method leads to significantly better results in comparison with the earlier methods in this context and the traditional procedures.

Keywords: Image denoising, Dictionary learning, Coherence, Domain adaptation, Image processing

$$
\begin{aligned}
& \text { مى كنند، با تكيه بر بُعد بسيار كمترى از هسببهاى يايه }
\end{aligned}
$$

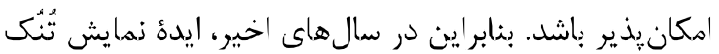

$$
\begin{aligned}
& \text { سيخنال كه مبتنىبر مفاهيم حسيرى فشرده يا نمونهبردارى }
\end{aligned}
$$

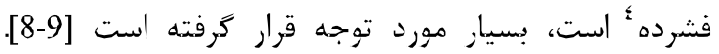

$$
\begin{aligned}
& \text { زموزهبردارى فشرده كه از كاربردهاى اصلى تجزيه تُونيه تُنُك } \\
& \text { محسوب مىشود در سالهاى اخير بهشدت مورد توجه قرار }
\end{aligned}
$$

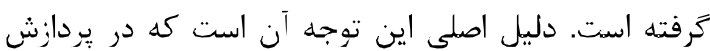

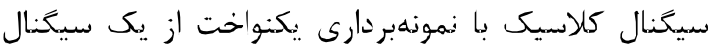

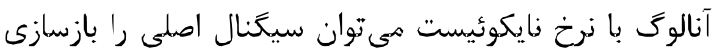

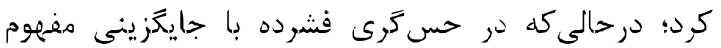

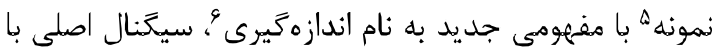

$$
\begin{aligned}
& \text { تعداد بسيار كمترى از اندازهكيرىها دز مقايسه با تعداد بهاد } \\
& \text { زموزههاى لازم قابل بازيابى خواهد بون. اندازهزيرى درحقيقت } \\
& \text { تركيبى خطى تصادفى از نموزهاى سيخنال است كه سيخنال }
\end{aligned}
$$

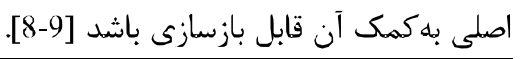

$$
\begin{aligned}
& { }^{3} \text { Basis } \\
& { }^{4} \text { Compressive sensing } \\
& { }^{5} \text { Sample } \\
& { }^{6} \text { Sensing }
\end{aligned}
$$

$$
\begin{aligned}
& \text { dodedo-1 } \\
& \text { كاربردهاى مختلف يردازش سيكنال تصوير در حوزههاى }
\end{aligned}
$$

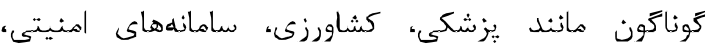

$$
\begin{aligned}
& \text { كاربردهاى صنغتى و نظامى موجب شده است تا اين زمينه }
\end{aligned}
$$

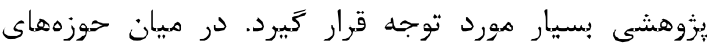

$$
\begin{aligned}
& \text { مختلف يردازش تصوير، بهرسازى يا حذف نوفه از سيخًال }
\end{aligned}
$$

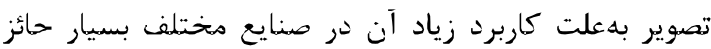

$$
\begin{aligned}
& \text { اهميت است [3-1]. الخوريتمهاى حذف نوفه ارائهشده تاكنون } \\
& \text { شامل دسته روشهاى طراحى فيلترهاى ساده و وفقى، }
\end{aligned}
$$

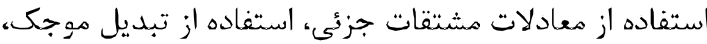

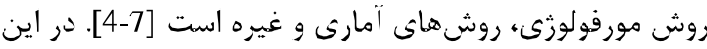

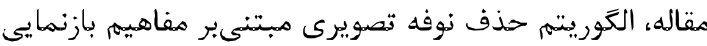

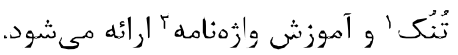

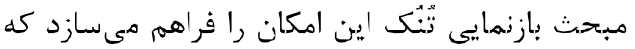

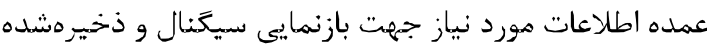

$$
\begin{aligned}
& \text { در يايكاههاى داده كه حجم بالايى از فضاى اطلاعات را اشغال }
\end{aligned}
$$

1 Sparse representation

${ }^{2}$ Dictionary learning 
بهمنظور حذف نوفه تصوير بهدست آورده است. اتمههاى وازمنامه در اين روش براساس تكههاى ^مختلف تصوير نوفهاى مشخص شده و با تنظيم شاخص تُنْكى هناسب، حذف نوفه

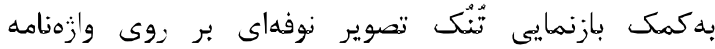
تعيينشده حاصل مى

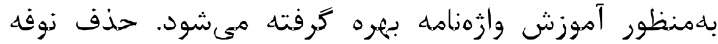
سيخنال تصوير بهلمك ضرايب حاصل از بازنمايى تُنُك

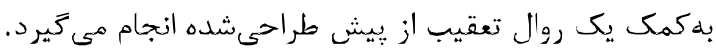

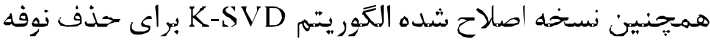

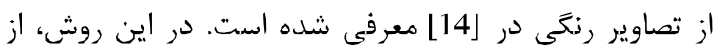

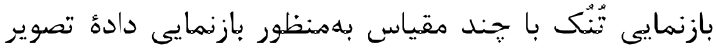
استفاده مىشود. در [15] الغوريتمى جهيت يادگيرى اتمهاى وازهنامه و

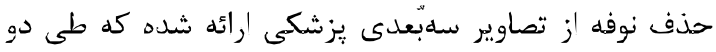

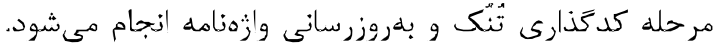

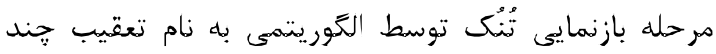

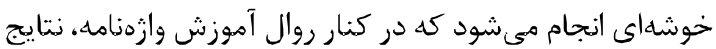
مطلوبى در حذف نوفه تصوير بدست مى دهد.

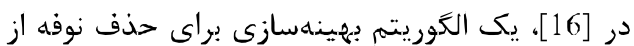

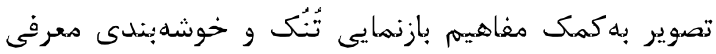

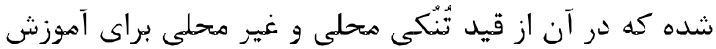
اتمها و خوشهبندى ساختارى استفاده شده است؛ همجرهنين

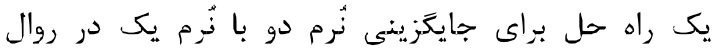

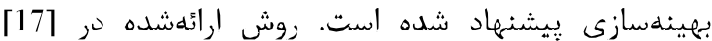

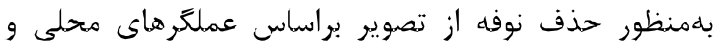

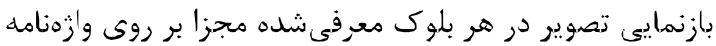

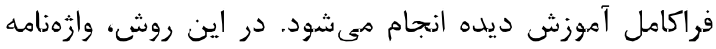
بهكاركفتهشده در روال حذف نوفه براساس تصوير نوفهاى

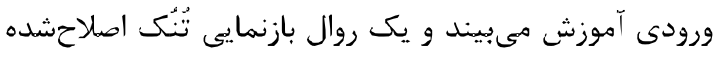

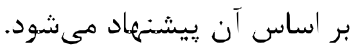

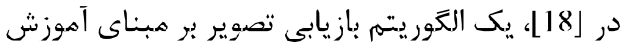

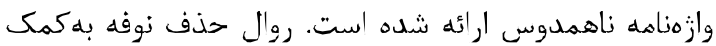
الخوريتم بهينهازى بيشنهمادشده و براساس كمينهسازى

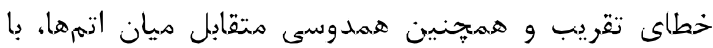
درنظرگرفتن قيودى صورت مى كيرد. اين قيود بلهمنظور

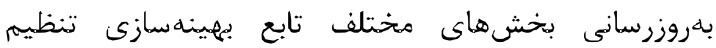

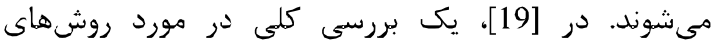

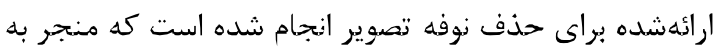
بازيابى تصوير و در اداهه افزايش تفكيكىيذيرى و قطعهبندى تصوير هىشود. بررسى هاى انجامشده از الحوزيتم ${ }^{8}$ Patch
مفهوم تُنْكى در حالت ايدهآل به معناى صفر بودن بيشتر مؤلفه هاى سيخنال در فضاى بازنمايى بوده اما درعمل

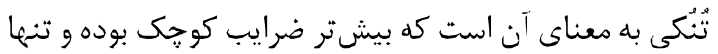

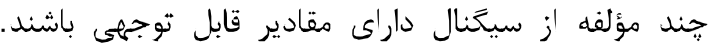

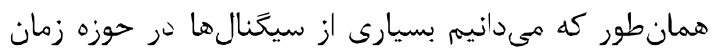

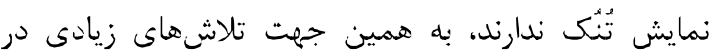

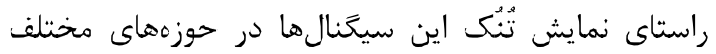
صورت گرفته است.

بسيارى از تبديلاتى كه در يردازش سيخنال براى

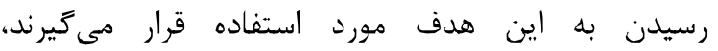
وازّنامههاى ' كاملى را فراهم مى آورند كه هر يك براى نمايش

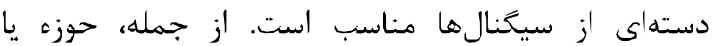

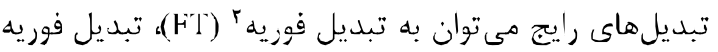

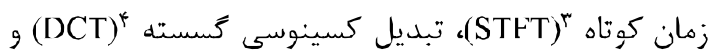
تبديل موجك گسسته (DWT) اشاره كرن. در سال هاى اخير، يادگيرى واززهنامه بهننظور بازنمايى

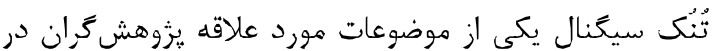

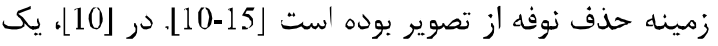

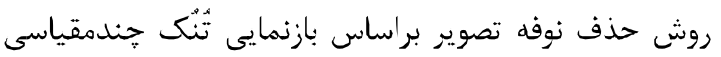

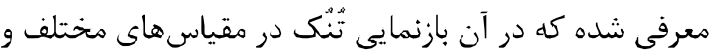
با توجه به ويثزَى هاى سيخنال تصوير انجام ميى شود. همجنين

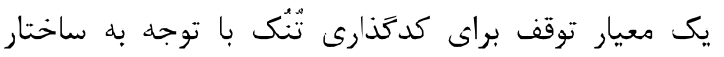

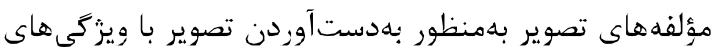

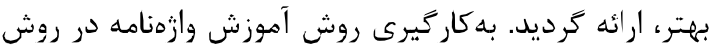
ييشنهادى، كيفيت تصوير حاصل از كام حذف نوفه را افزايش داده و موجب بيجيدگى محاسباتى كمتر مىشود. در ل111] روش حذف نوفه محلى-تطبيقى براساس خوشهبندى تصوير نوفهاى در نواحى داراى ساختار هندسى مشابه ارائه شد. در روال خوشهبندى مطرحشده از توابع مشتق، ركرسيون و توابع كرنل بهمنظور محاسبه مشخصه وزن محلىى استفاده مى شوده.

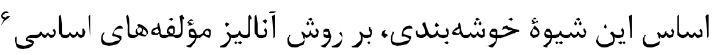
استوار است [11]. استفاده از مفاهيم بازنمايى تُنْك و ايدة آموزش وازْهنامه

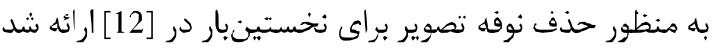

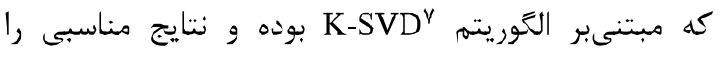

\footnotetext{
1 Dictionary

${ }^{2}$ Fourier Transform

${ }^{3}$ Short Time Fourier Transform

${ }^{4}$ Discrete Cosine Transform

${ }_{6}^{5}$ Discrete wavelet Transform

${ }^{6}$ Principle component analysis (PCA)

${ }^{7} \mathrm{~K}$-Singular value decomposition
} 


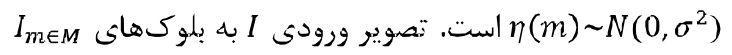

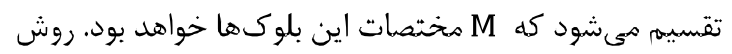

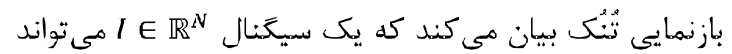

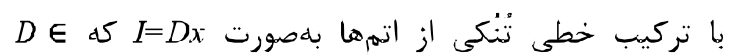

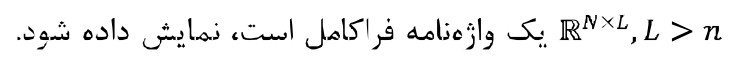

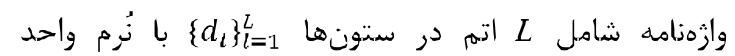

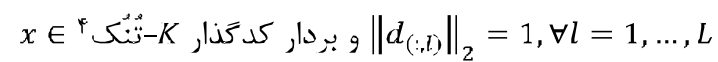
شامل ضرايب بازنهايى سيكنال I خواهد بود [-21

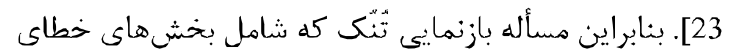

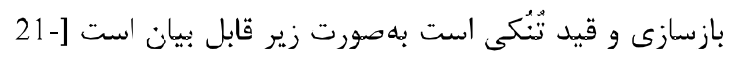

$$
\begin{aligned}
& x^{*}=\arg \min _{x}\|I-D x\|^{2} \\
& \text { s.t. }\|x\|_{0} \leq K
\end{aligned}
$$

تعداد ضرايب غير صفر در x بهصورت كار

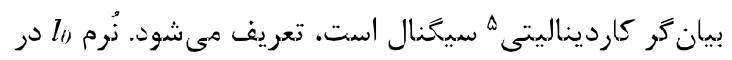

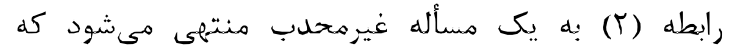

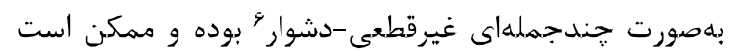

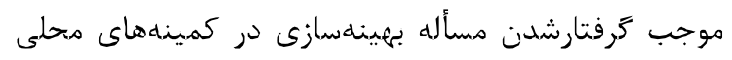

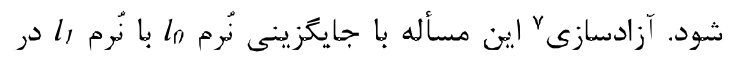
] [24 كزارش شده است.

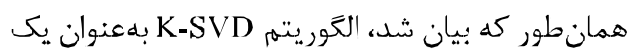

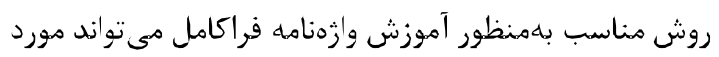

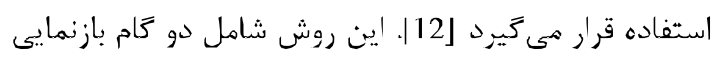

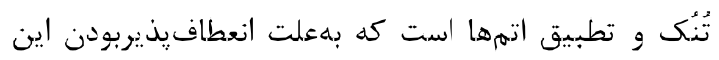

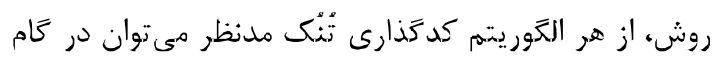

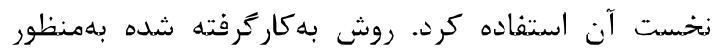

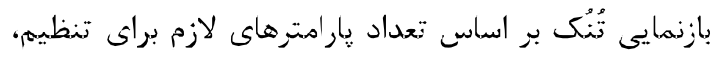

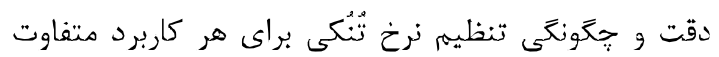

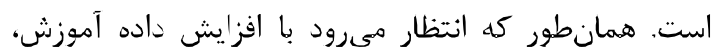
سرعت هممر ايى الكوريتم نيز كاهش مى يابد. تنظيم مناسب

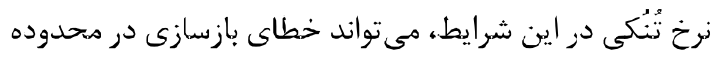

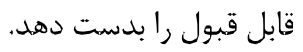
تاكنون روشهاى يادكيرى وازمنامه متعددى ارائه شده

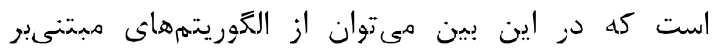

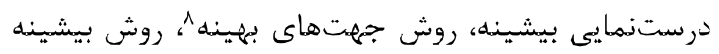

$$
\text { احتمال پِينه نام برد [26-25]. }
$$

\footnotetext{
${ }^{4} \mathrm{~K}$-sparse

${ }^{5}$ Cardinality

${ }^{6}$ Non-deterministic polynomial hard (NP-Hard)

${ }^{7}$ Relaxation

${ }^{8}$ Method of optimal directions(MOD)
}

روش پايه در اين زمينه است، شروع و درنهايت به روالهاى

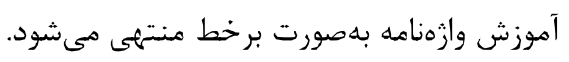

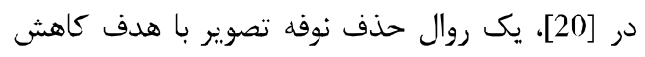

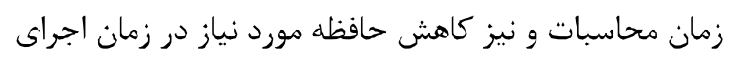

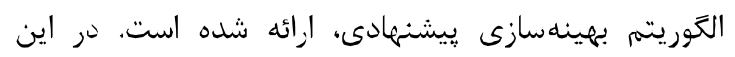

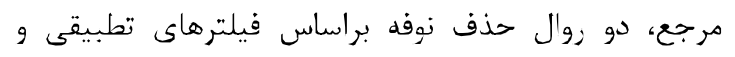

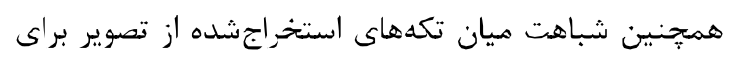

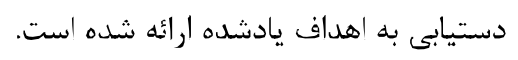

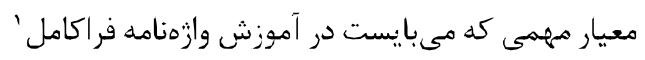

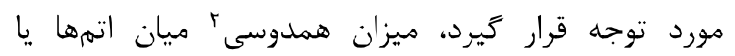

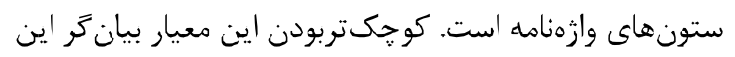

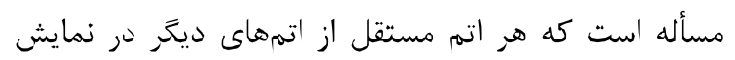

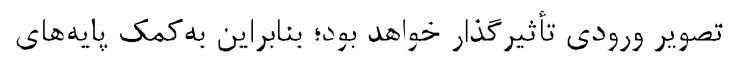
فضايى تا حد ممكن مستقل، كمترين خطاى تقريب در نمايش تصني تُنُك سيحنال تصوير بهنست مئى آيد.

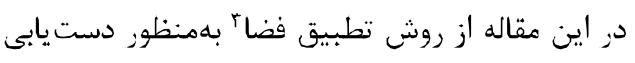

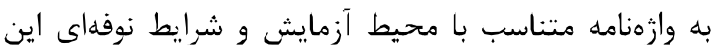

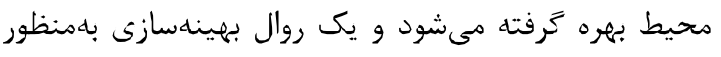

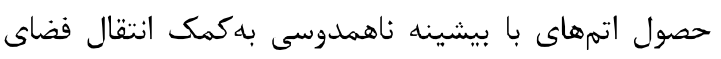

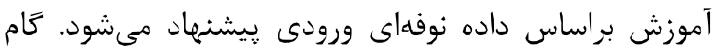

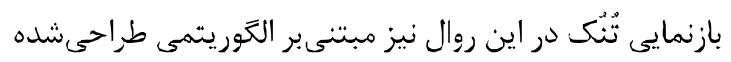
است كه اتمهاى با بيشترين همدوسى نسبت به به داده تصوير

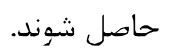
در بخش دوم اين مقاله مسأله حذف نوفه از سيكنال

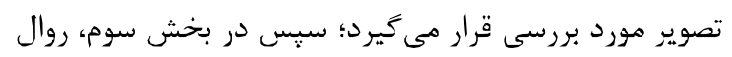

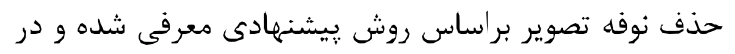

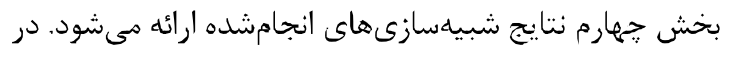

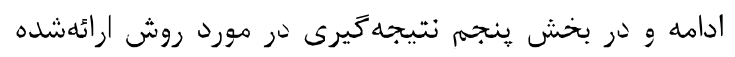
بيان مىشود.

\section{r-تعريف مسئله}

سيخنال تصوير در مواجهه با نوفه سفيد كوسى بلصورت زير

$$
\text { قابل مدلشدن خطى است: }
$$

$Y(m)=I(m)+\eta(m)$

كه در آن Y، I و و إهترتيب ماتريس داده سيخنال

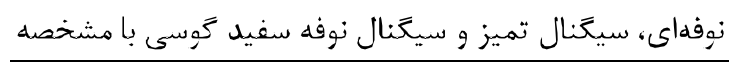

${ }^{1}$ Overcomplete

${ }^{2}$ Coherence

${ }^{3}$ Domain adaptation 
فضاى نوفهاى تصوير مشاهدهشده در محيط آزمايش، تطبيق آزيق

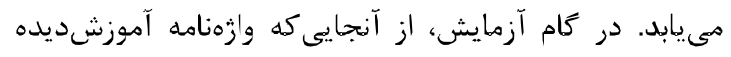

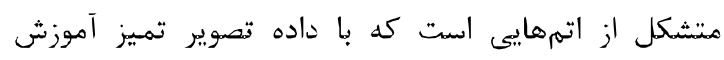

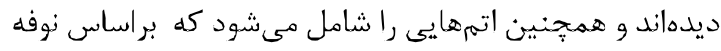

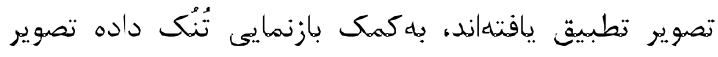

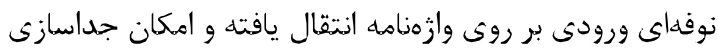

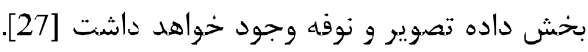
اكر فرض كنيم كه وازمناهه اوليه

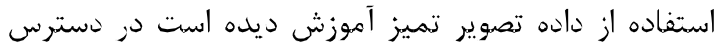

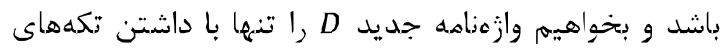

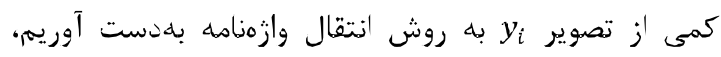

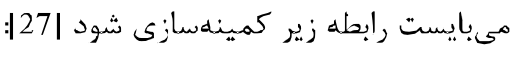

$$
\begin{array}{r}
L(X, D)=\min _{x, D} \sum_{i}^{m}\left\|y_{i}-D x_{i}\right\|_{2}^{2} \\
+\lambda_{1}\left\|D-D_{0}\right\|_{F}^{2}
\end{array}
$$$$
\text { s.t. } \forall i,\left\|x_{i}\right\|_{0} \leq K
$$$$
\forall j=1,2, \ldots, l, d_{j}^{T} d_{j} \leq 1
$$

در اين رابطه

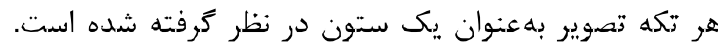

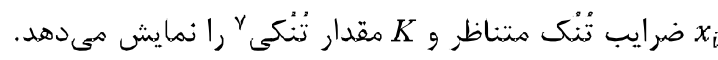

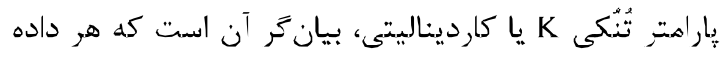

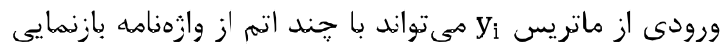

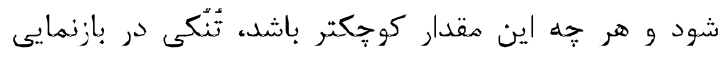

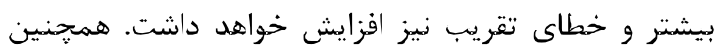

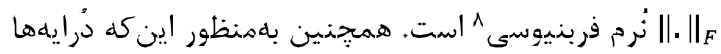

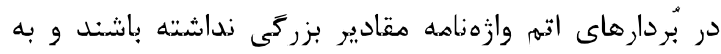

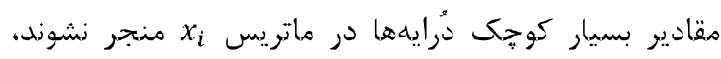

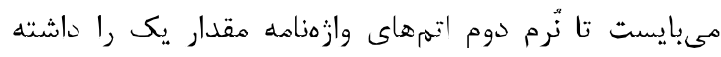

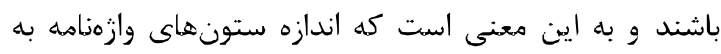

$$
\text { مقدار يك نرماليزه شوند. }
$$

بخش نخست در اين رابطه بيان خر خطاى تقريب است

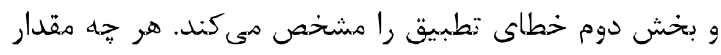

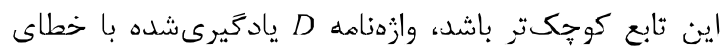
تقريب بازنمايى تُتُك كمترى به وازَّهن وارنامه اوليه

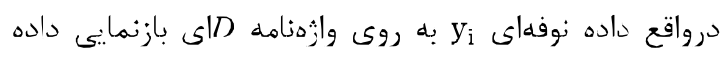
مىشود كه شباهت زيادى به وازونامه

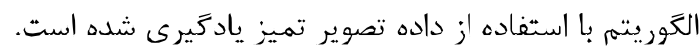

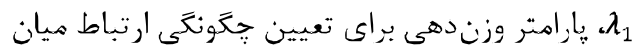
فضاى اوليه و فضاى تطبيق است. اكر دو فضا شبيه باشند،

${ }^{7}$ Cardinality

${ }^{8}$ Frobenius

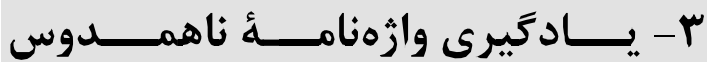 براساس روش تطبيق فضا}

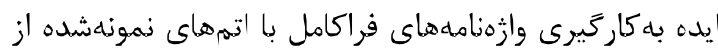

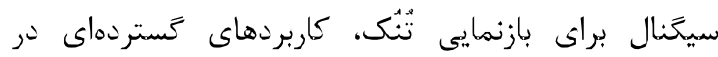

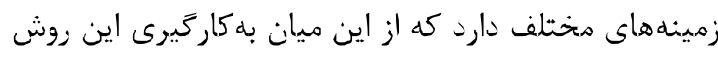
در حوزه حذف نوفه تصوير بسيار نويا و جديد است [9-8)]

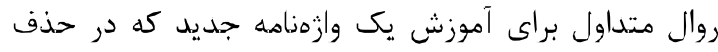

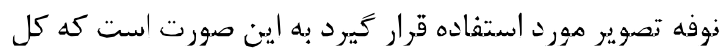

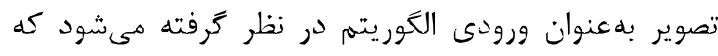

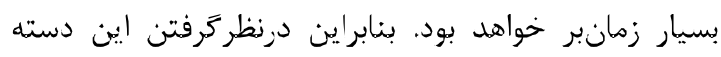

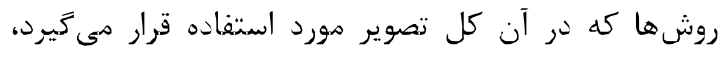

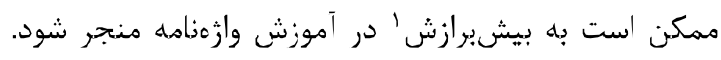

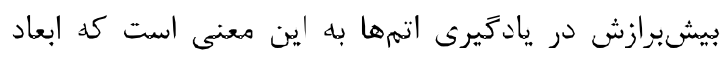

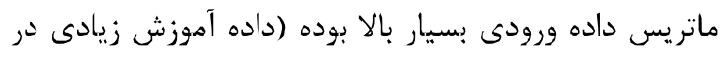
دسترس است) و تعداد اتمها يا ستتونهاى وازٔمنامه بهمنظور

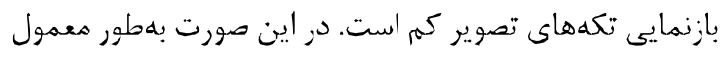

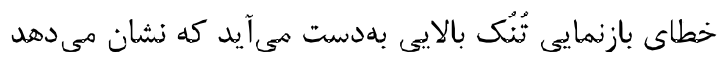

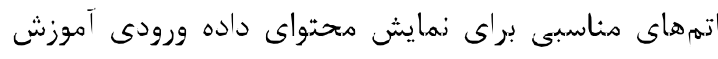

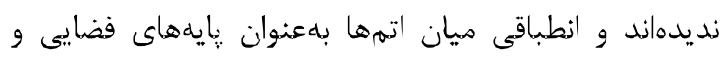
مجتواى ساختارى داده تصوير وجود ندارد.

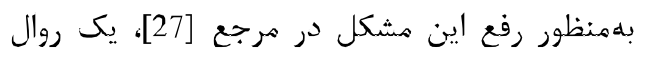

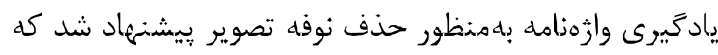

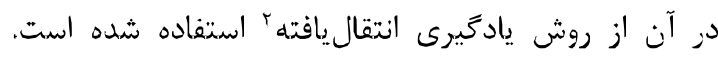

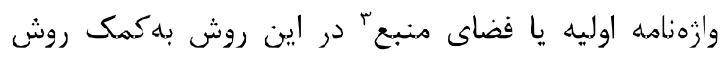

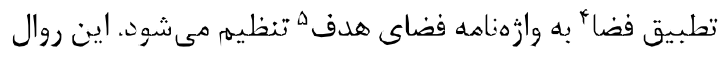

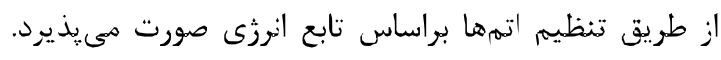

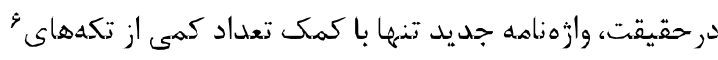

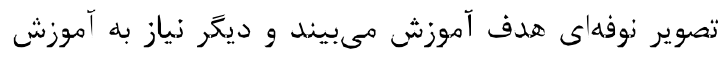

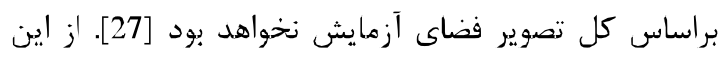

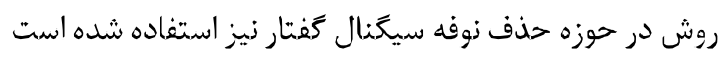

براساس روش تطبيق فضا، در ابتدا يك وازهنامه

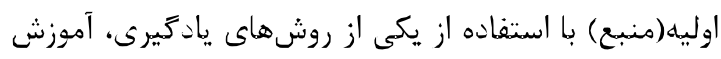

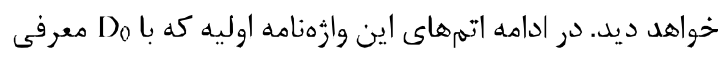

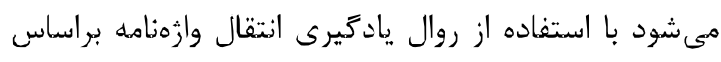

\footnotetext{
${ }^{1}$ Over fitting

Transfer learning

${ }^{3}$ Source domain dictionary

${ }^{4}$ Domain adaptation

${ }^{5}$ Target domain dictionary

${ }^{6}$ Patch
} 
در اين رابطه،

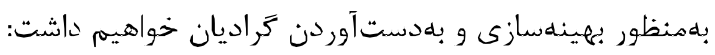

$$
\begin{aligned}
& \frac{\partial F}{\partial D}=0 \rightarrow \frac{\partial \operatorname{tr}\left(D^{T} D A\right)}{\partial D}=2 D A, \\
& \frac{\partial \operatorname{tr}\left(D^{T} B\right)}{\partial D}=B, \\
& \frac{\partial \operatorname{tr}\left(\left(D-D_{0}\right)\left(D-D_{0}\right)^{T}\right)}{\partial D}=2\left(D-D_{0}\right)
\end{aligned}
$$

$$
\text { در نتبجه بdدست مى آيد: }
$$

$$
\begin{aligned}
& 2 D \Lambda-2 B+2 \lambda_{1}\left(D-D_{0}\right)=0 \rightarrow D= \\
& \left(B+\lambda_{1} D_{0}\right)\left(A+\lambda_{1} I\right)
\end{aligned}
$$

I در اين رابطه ماتريس يكه است. اكر داده آموزش

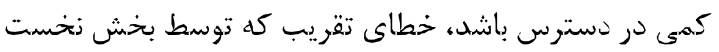

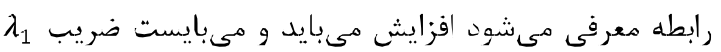
بزركتر انتخاب شود تا اثر بخش دوم رابطه بيشتر شوده.

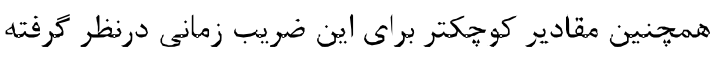

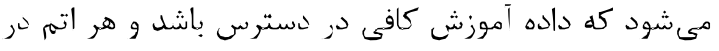

وازمنامه D بهراحتى بتواند تصوير ورودى را بازسازى كند.

\section{ا-"- يادكيرى وازهزامه براساس ناهمدوسى}

از آنجايى كه استفاده از وازثهنامه ناهمدوس مطابق با آنجهه در

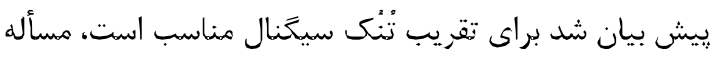

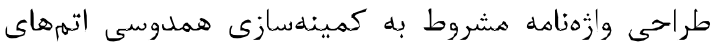

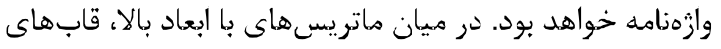

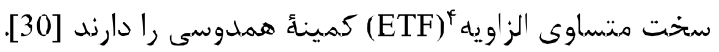

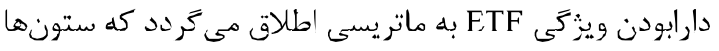
در آن به طور كامل از يكديخر مستقل بوده و يا كمترين ميزان

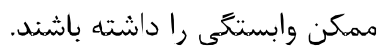

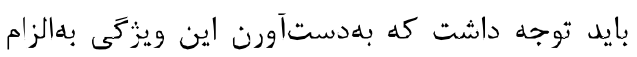
براى هر وازمنامه با ابعاد دلخواه ممكن نخواهد بود. بنابراين حل مسأله بهصورت تقريبى انجام خواهد كرفت. يارامتر مهاهم

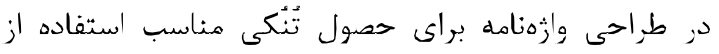
يارامتر همدوسى $\mu$ آن وازهنامه است كه بهصورت مقدار هطلق بزرگترين حاصل ضرب نرونى اتمهاى مجزاى وازمناهه تعريف

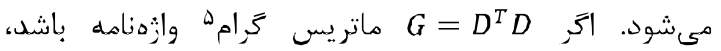
همدوسى بيشينه مقدار مطلق عناصر غيرقطرى در G است.

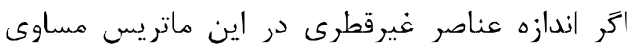

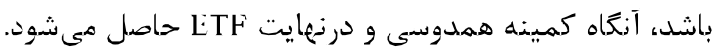

${ }^{4}$ Equiangular tight frame

${ }^{5}$ Gram matrix
يعنى وازهنامد اوليه با داده تصوير آهوزش ديده باشد كه همان دانه در مرحله آزمايش نوفهاى شده باشد، D به وامه

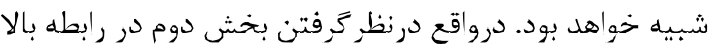

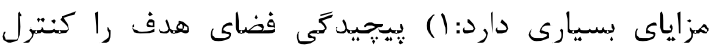

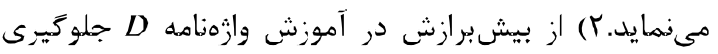

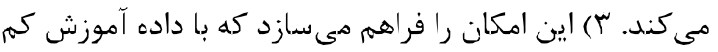
بتوان دقت حذف نوفه بالايى را بهدست آورد.

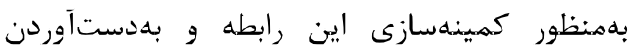

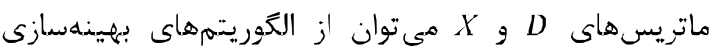

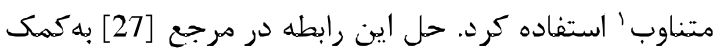
الكوريتم متناوب ارائه شده است. در اين الكوريته در ابتدا

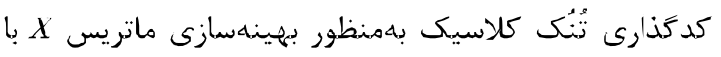
وازهناهه ثابت D انجام و سيس بهروز

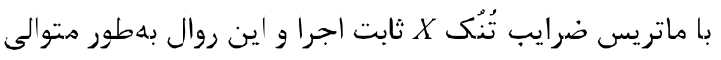

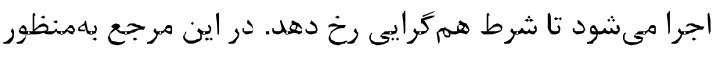

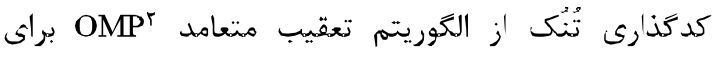

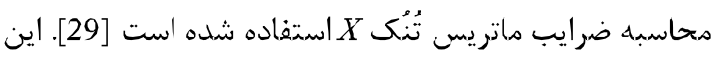

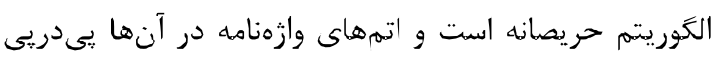
انتخاب مىشوند. در اين روش شامل محاسبه حاصل ضرب إنه

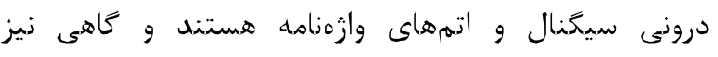

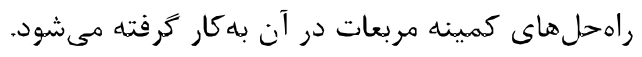

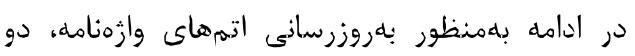

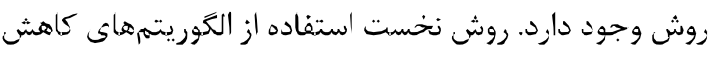

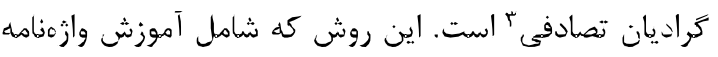

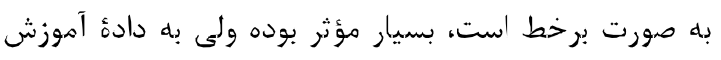

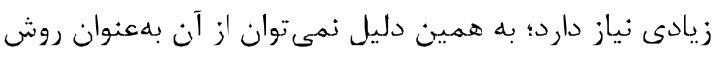

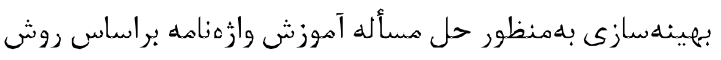
تطبيق فضا استفاده كرد. روش ديخر استفاده از گراديان تابع موردنظر و صفر قراردادن آن است؛ يعنى 0 آن

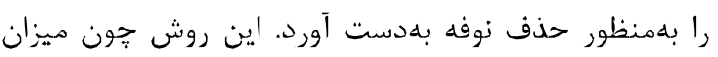
داده آموزش حائز اهميت نيست مورد توجه قرار هى كيرد.

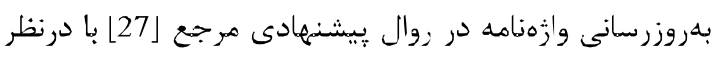

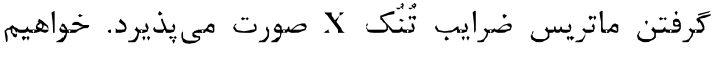

$$
\begin{gathered}
F=\min _{D} \sum_{i}^{m}\left\|y_{i}-D x_{i}\right\|_{2}^{2}+\lambda_{1}\left\|D-D_{0}\right\|_{F}^{2} \\
=\min _{D}\left(\operatorname{tr}\left(y_{i}^{T} y_{i}\right)+\operatorname{tr}\left(D^{T} D A\right)-2 \operatorname{tr}\left(D^{T} B\right)+\right. \\
\left.\lambda_{1} \operatorname{tr}\left[\left(D-D_{0}\right)\left(D-D_{0}\right)^{T}\right]\right)
\end{gathered}
$$

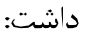

\footnotetext{
${ }^{1}$ Alternating

${ }^{2}$ Orthogonal matching pursuit

${ }^{3}$ Stochastic gradient descent
} 
نخواهد بود و داده نمىتواند بلدرستى بر زوى تعداد كم

اتمهاى وازثمنامه كد شود [32].

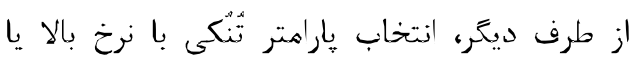

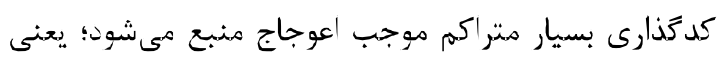
تعدان اتمها در وازهنامه تصوير براى بازنمايى درست آن بيشتر از حد نياز بوده و در اين صورت خطاى تقريب افزايش مى يابد.

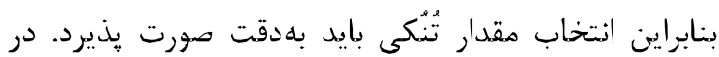

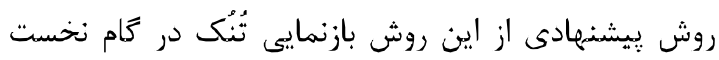

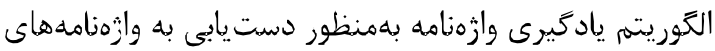
با همدوسى متقابل بالا استفاده مىشود.

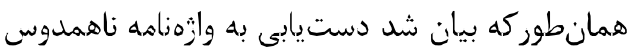
بهصورت دقيق ممكن نيست و اين مسأله هنغامى كم ابعاد

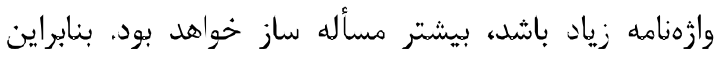

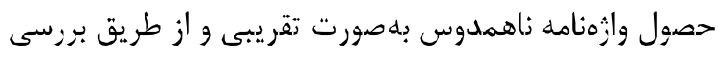
ماتريس كرام ممكن خواهد بود. ماتريس كرام يك وازثمزامه ناهمدوس نرماليزهشده به ماتريس يكه واحد شبيه خواهد بود.

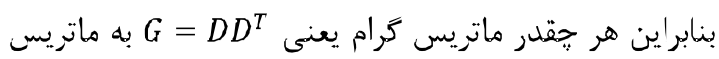

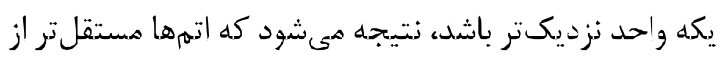
يكديك, طراحى شدهاند. بنابراين بِيشنهاد شدد كه به رابطه (ז) بخش مرتبط با همدوسى وازمناهه تحت آموزش اضافه شون. در اين صورت تابع بجينهسازى بهصورت زير خواهد بود:

$F_{\text {Proposed }}=\min _{D} \sum_{i}^{m}\left\|y_{i}-D x_{i}\right\|_{2}^{2}+$

$\lambda_{1}\left\|D-D_{0}\right\|_{F}^{2}+\lambda_{2}\left\|D D^{T}-I\right\|_{F}^{2}$

$F_{\text {Proposed }}=\min _{D}\left(\operatorname{tr}\left(y_{i}^{T^{T}} y_{i}\right)+\right.$

$\operatorname{tr}\left(D^{T} D A\right)-2 \operatorname{tr}\left(D^{T} B\right)+\lambda_{1} \operatorname{tr}[(D-$

$\left.D_{0}\right)\left(D-D_{0}\right)^{T}+\lambda_{2} \operatorname{tr}\left[\left(D D^{T}-\right.\right.$

I) $\left.\left.\left.\left(D D^{T}-I\right)^{T}\right]\right]\right)$

بخش سوم رابطه (9) تفاضل ماتريس 5رام از ماتريس

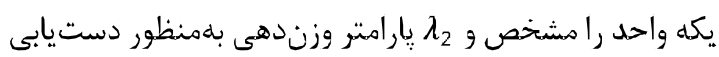

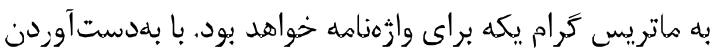
كراديان اين تابع خواهيم داشت:

$$
\begin{aligned}
& \frac{\partial F_{\text {Proposed }}}{\partial D}=2(D A-B)+ \\
& 2 \lambda_{1}\left(D-D_{0}\right)+4 \lambda_{2} D\left(D D^{T}-I\right)
\end{aligned}
$$

بخش نخست در اين رابطه مربوط به كاهش خطاى

تقريب داده نوفه، بخش دوم مربوط به به يافتن وازمنامه نوفه با دراي

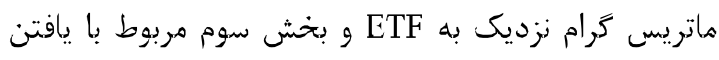

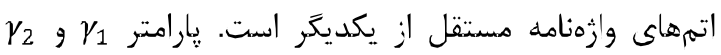

همدوسى اتمهاى واثرنامه D بهصورت زير قابل تعريف است

$$
\mu(D)=\max _{1 \leq i, j \leq L, i \neq j}\left|d_{i} \cdot d_{j}\right|
$$

بنابراين با توجه به ويزّكى هاى بيانشده براى الكوريتهم

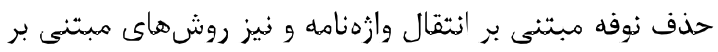

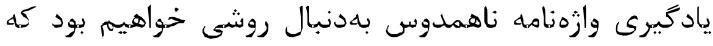

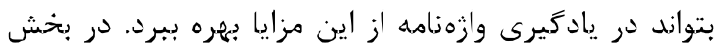

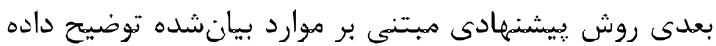

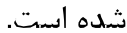

$$
\text { r-r - روش بيشنيهادى }
$$

با توجه به موارد بيانشده در بخشهاى قبل تبل اين نتيجه حاصل

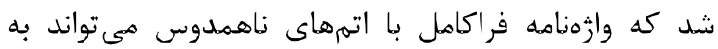
خطاى بازنمايى كمى منجر شود؛ زيرا هر اتم مستقل از اتمهاى

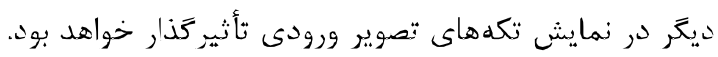

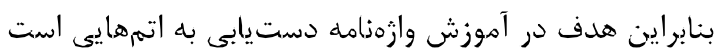

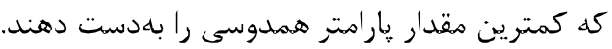

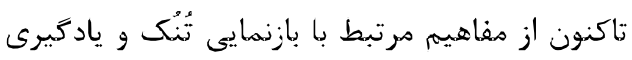

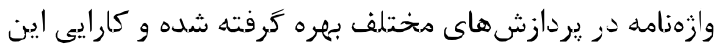

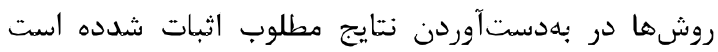

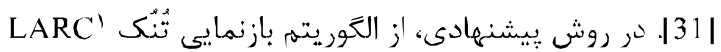

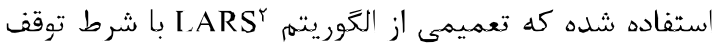

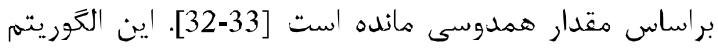

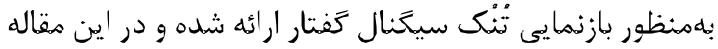
در راستاى حذف نوفة داده تصوير به كار كرفته مى شيود [32].

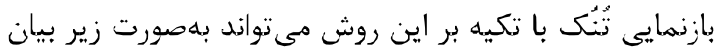

$$
x^{*}=\operatorname{LARC}(D, x, K, C o h)
$$

ازآنجايى كه الكوريتم بازنمايى تُنْى LARC بر طبق

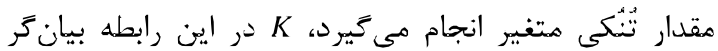
بيشينه هقدار اين نرخ براى هر تكه دادة ورودى است. همجحنين، ياراهتر Coh بيانكر ميزان همدوسى هيان اتهم-دانه

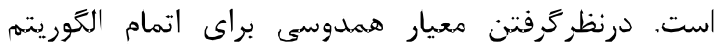

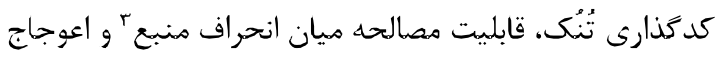

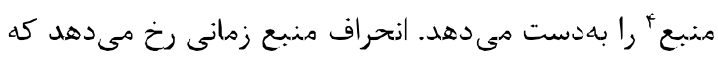

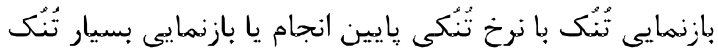

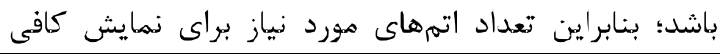

\footnotetext{
Least angle regression with coherence criterion

${ }^{2}$ Least-angle regression

${ }^{3}$ Source distortion

${ }^{4}$ Source confusion
} 


$$
I_{\text {out }}=\frac{\hat{I}}{\hat{\imath}+I_{\text {in }}} . I_{\text {in }}
$$

در اين رابطه، In سيخنال نوفهاى ورودى خهواهد بود كه در بهره ساختهشده براساس داده تصوير حاصل از وازمنامه ناهمدوس ضرب و تصوير تميز را نتيجه ميدهد.

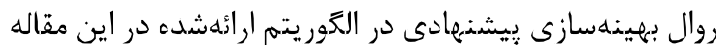
بلدمنظور حذف نوفه تصوير در ادامه آورده شده است:

دادة ورودى الخَوريته: تكههاى تصوير لإن،

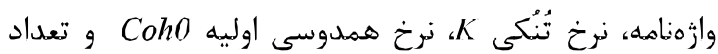
تخكرار خروجى الكَوريتم: وازثنامه D و ضرايب تُنْك

$$
0 \leftarrow B, A \text {, } 0
$$$$
\text { r. براى 1:I }
$$

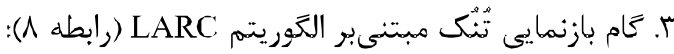
$\min _{x, D} \sum_{i}^{m}\left\|y_{i}-D x_{i}\right\|_{2}^{2}$ s.t. $\forall i,\left\|x_{i}\right\|_{0} \leq K$, Coh $\geq$

\section{Coho}

F. براى دادهُ ورودى y و ضرايب تُنُك متناظرشان $A+x_{i} x_{i}^{T} \rightarrow A$

$B y_{i} x_{i}^{T} \rightarrow B$

ه. گام يادكيرى وازمنامه و نرماليزهسازى وازمنامهُ نهايى (رابطه

$F_{\text {Proposed }}=\min _{D} \sum_{i}^{m}\left\|y_{i}-D x_{i}\right\|_{2}^{2}+\lambda_{1}\left\|D-D_{0}\right\|_{F}^{2}+$ $\lambda_{2}\left\|D D^{T}-I\right\|_{F}^{2}$

و. اكر i<I باشد باز گشت به كام دوم.

\section{P - زتايج شبيهسازى}

در بخش كذشته روال حذف نوفه تصوير با بهكارگيرى ايده

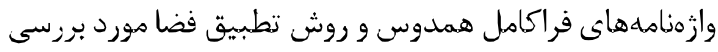

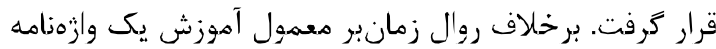
جديد بههنظور حذف نوفه تصوير كه در آن كل تصوير بهعنوان

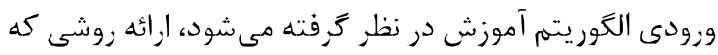

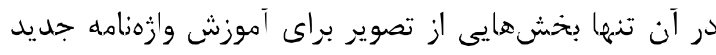

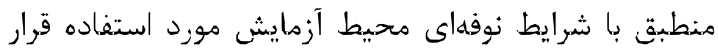

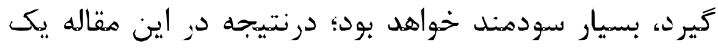
روال يادگيرى وازمنامه بههنظور حذف نوفه تصوير بيشنهياد داده شد كه در آن از روش وازهناهd إنتقال يافته استفاده شهده

در روش بيشنهيادى اتمهاى وازمناهه فضاى هدف D كد منطبق با شرايط محيط نوفهاى است، براساس اتمهاى وازمنامه اوليه D بهكمك روش تطبيق فضا بهروز مىشوند. اين روال بهينهسازى اتمها بهكمى انتقال اتمها براساس معيار انرزى بهى
مصالحه ميان اين بخشها را كنترل مى كند. با توجه به رابطه

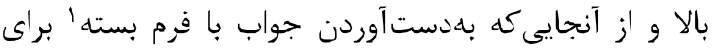

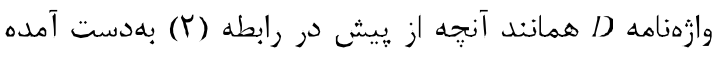
است، امكانيذير نيست؛ بنابراين بايد از يكى التوريته

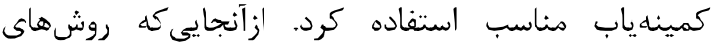
بازنمايى تُنْك انعطاف يذير بوده و از نتايج حاصل از آنها در هر روش يادكيرى وازٔنامه مىتوان استفاده كرد، از يادكيرى

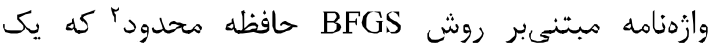

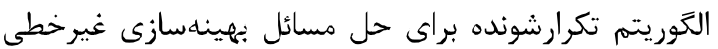
بدون قيد خواهد بود [34]. اين روش تقريبى براى روش بهينهسازى نيوتون بوده و نسخه حافظه محدوششدهاى بوني از روش بجينهسازى BFGS است كه بهمنظور بهينهسازى در مسائل با ابعاد بالا طر احى شده است. اين الكوريتم مشابه روش

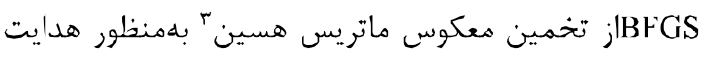

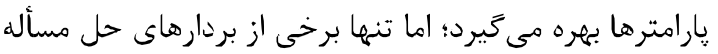

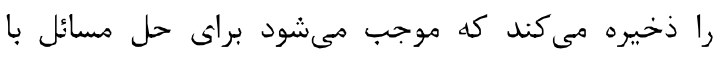
بارامترهاى زياد بيشتر مورد توجه قرار كيرد.

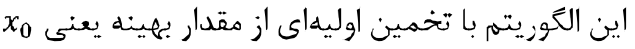
شروع و بهطور تكرارشونده براى تخمين مقادير بهتر 1.

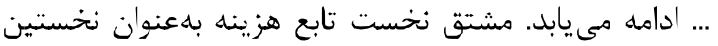
قدم براى شروع الكوريتم و بهمنظور عملكرد براساس تندترين

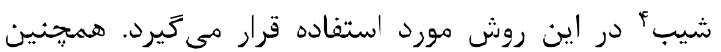
ماتريس هسين ه (مشتق دوم) براساس آن تخمين زده مي رشود.

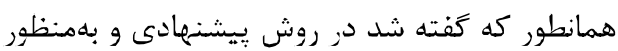
بهروزرسانى اتمها در واززهنامه تصوير بهكمى روش حافظه

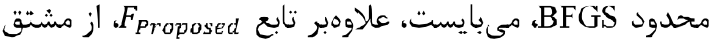
آن يعنى

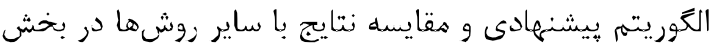
بعد آورده شده است.

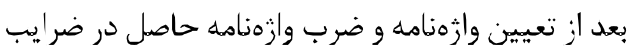
تُنُك، داده تصوير أ بهدست مى آيد كه مىبايست تحته

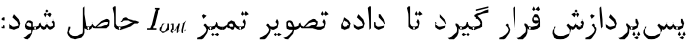

$\hat{I}=D \cdot x$

در اين رابطه، D ماتريس وازمنامه تطبيقيافته براساس

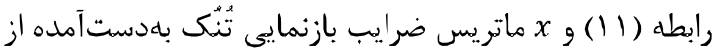
رابطه (^) است.

${ }^{1}$ Closed form

${ }^{2}$ Limited-memory Broyden-Fletcher-Goldfarb-Shanno

${ }^{3}$ Hessian matrix

${ }^{4}$ Stecpest descent method

${ }^{5}$ Hessian matrix 
انتخابشده از تصوير ورودى بلمنظور ساخت ماتريس داده Y،

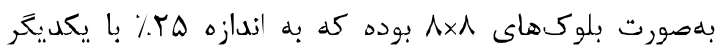

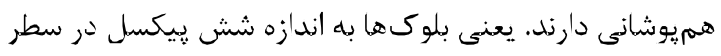

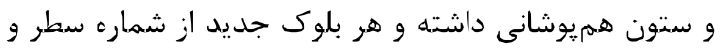

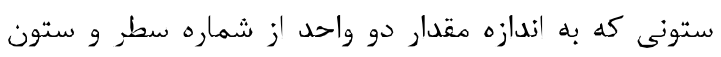
بلوك قبلى بيشتر است، شروع مى بـوند

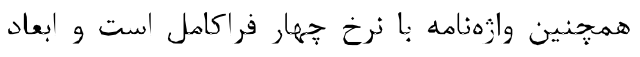

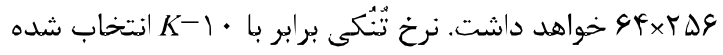

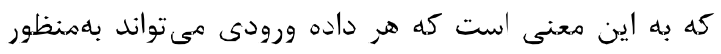

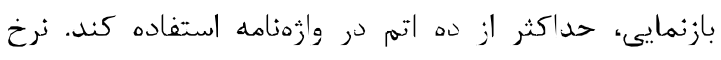

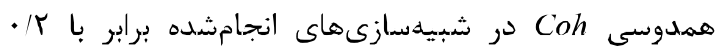

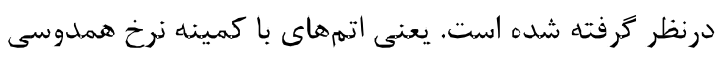

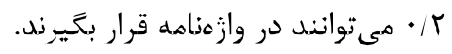

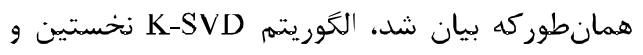

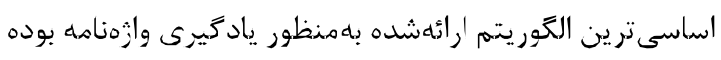

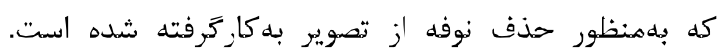

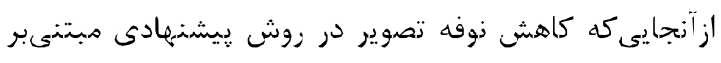

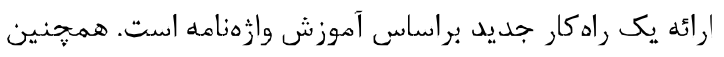

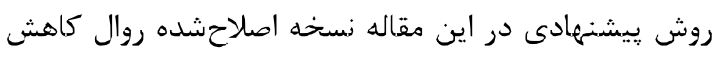

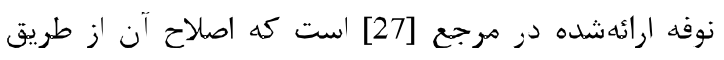

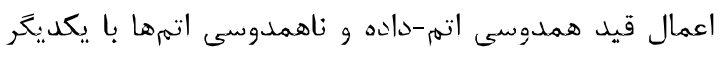

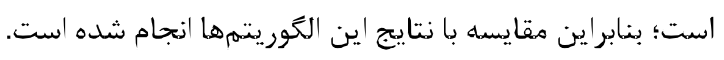
در ابتدا وازمهناهه اوليه يا منبع

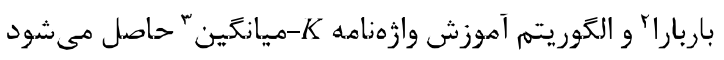

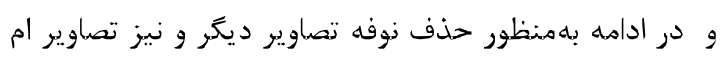

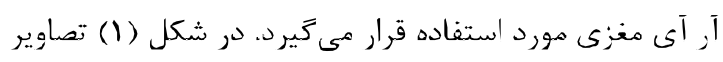

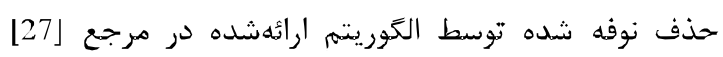

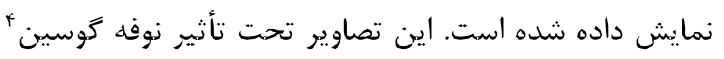

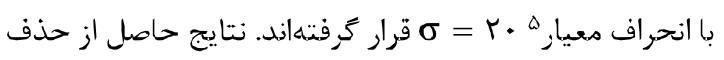

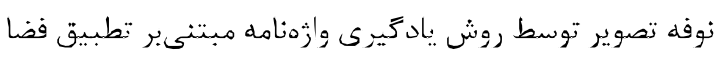

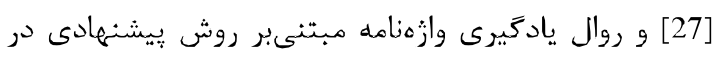

$$
\text { شكل (T) آورده شده است. }
$$

همجنين وازمنامه تصوير توسط يكصد تكه از تصوير

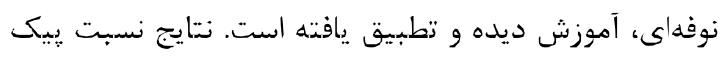

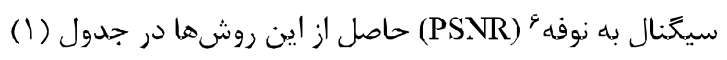

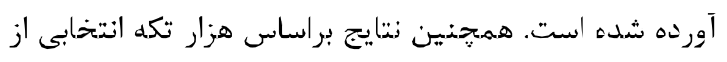

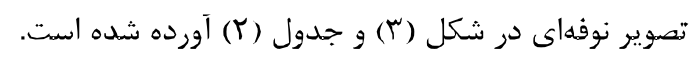

\footnotetext{
${ }^{2}$ Barbara

${ }^{3} \mathrm{~K}$-means

${ }^{4}$ Gaussian noise

${ }^{5}$ Standard deviation

${ }^{6}$ Peak signal to noise ratio
}

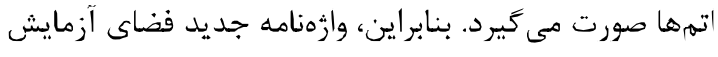
تنها بهكمى تعداد كمى از تكههاى تصوير نوفهاى هدف

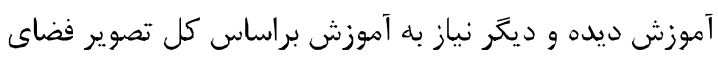
آزمايش نخواهد بود.

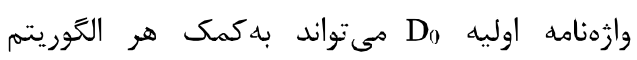
يادكيرى وازمنامه مدنظر و در دسترس به كمك هر داده تصوير

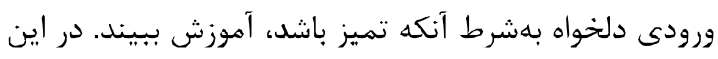

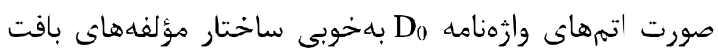
تصوير را بازنمايى كرده و مى توانند در روال حذف نوفه تصوير مبتنىبر روش تطبيق فضا به كاركرفته شوند.

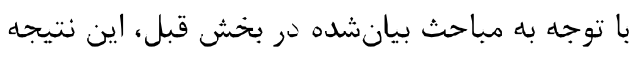
حاصل شد كه وازّهنامه فراكاهل با بيشينه ناهمدوسى اتمهها مىتواند به خطاى بازنمايى كمى منجر شود؛ زيرا هر اتم وازمنامه مىتواند مستقل از ساير اتمها در نمايش داده تصوير باندي

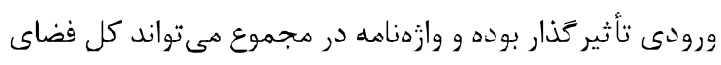

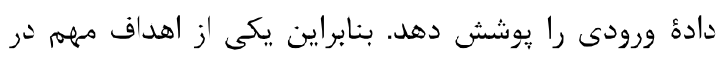

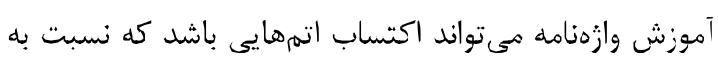
يكديخر كمترين مقدار معيار همدوسى را داشته باشند. همانطور كد بيان شد، دست يابى دقيق به اين دسته

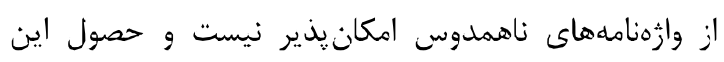

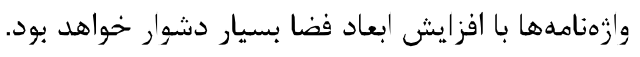

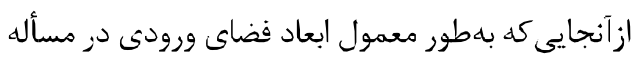
حذف نوفه كه با تكههاى تصوير سروكار دارد، بالا است، ابعاد

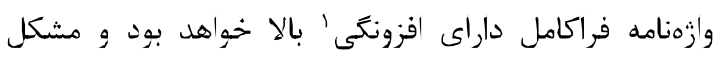
بيانشده يابرجا است؛ بنابراين انتظار دستيابى به تقريبى از

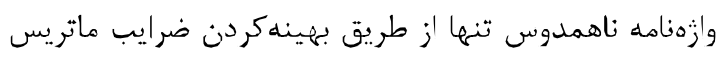

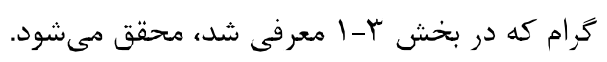

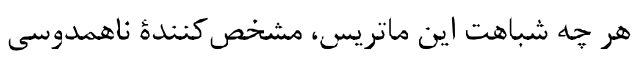
اتمهاى وازمنامه نرماليزهشده به ماتريس يكه واحد باشد، نتيجه مى شود كه اتمها تا حد ممكن نسبت به يكديخر ناهمدوس طراحى شدهاند؛ بنابراين در روش جديد حذف نوفه

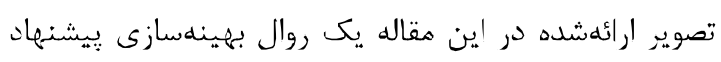
شد كه در آن بخشى مرتبط با همدوسى اتمهاى وازٔنامه در ئر

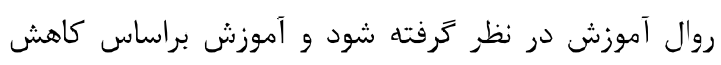

$$
\text { خطال تقريب در كنار كاهش هدوسى اتمها صورت يذيرد. }
$$

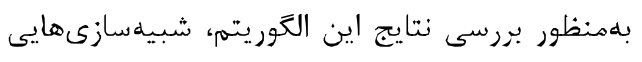
بر روى دادة تصوير طبيعى و يزشكى انجام شده است.

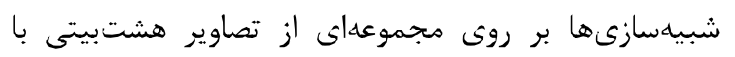

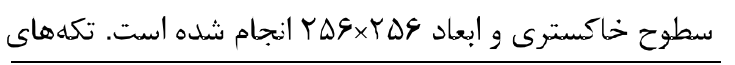

\footnotetext{
${ }^{1}$ Redundancy
} 

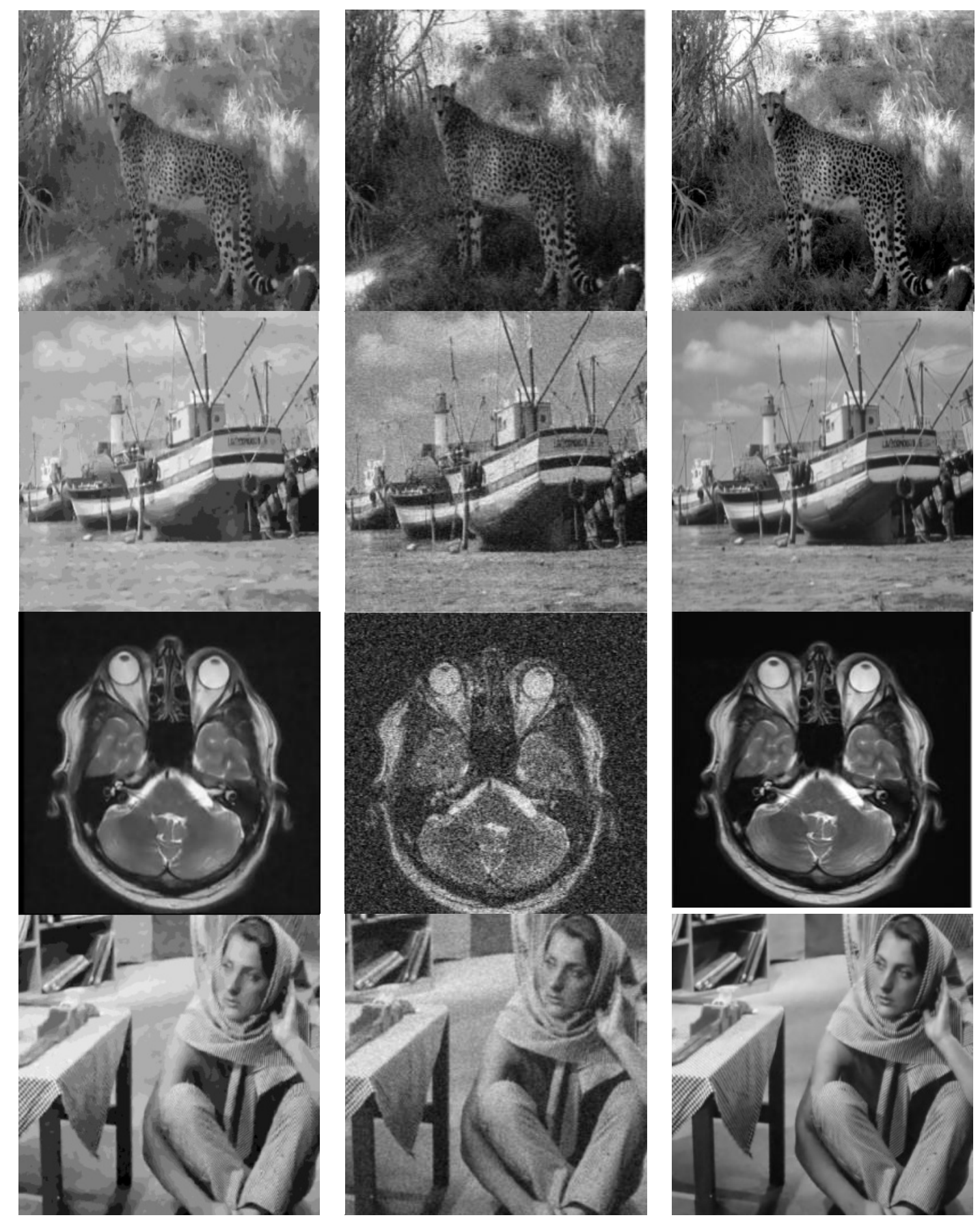

(شكل -1): نتايج حذف نوفه تصوير حاصل از به كارگيرى روش بيشنهادى در حضور نوفه توسين و •r = 0 براى يكصد تكه. ستون سمت

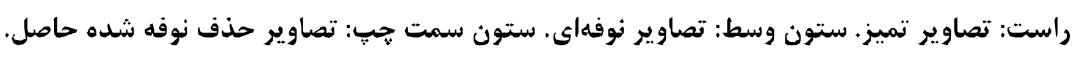

(Figure-1): Results of image denoising based on the proposed algorithm in the presence of Gaussian noise with $\sigma=20$ for 100 patches of noisy image. Right column: Clean images. Middle column: Noisy images. Left column: Denoised image. 

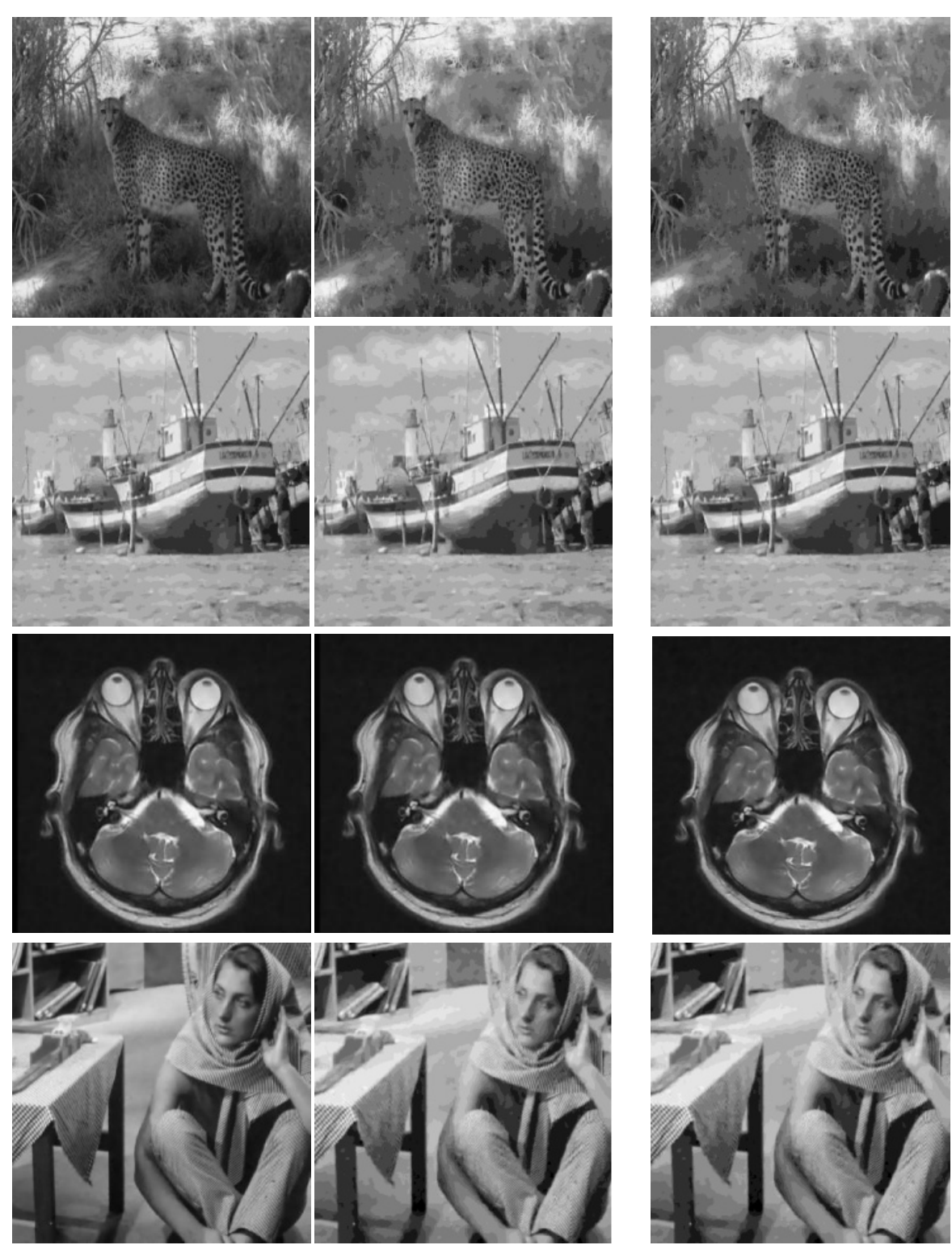

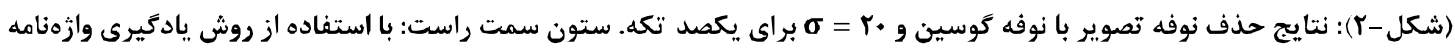

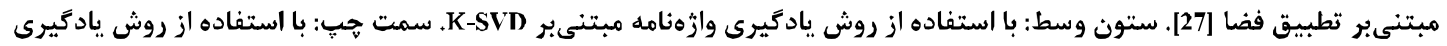

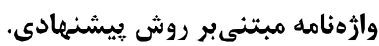

(Figure-2): Results of image denoising in the presence of Gaussian noise with $\sigma=20$ for 100 patches. Right column: The dictionary learning method based on domain adaptation [27]. Middle column: The denoising algorithm based on K-SVD dictionary learning method. Left column: The proposed method.

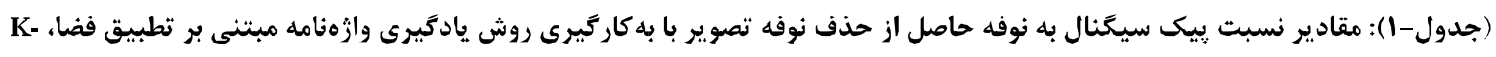

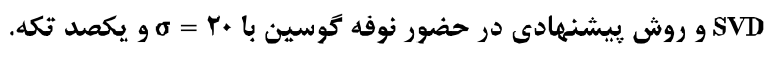

(Table-1): Results of PSNR values of different image denoising approaches such as domain adaptation-based dictionary learning, $K-$ SVD and the proposed method in the presence of Gaussian noise with $\sigma=20$ for 100 patches.

\begin{tabular}{|c|c|c|c|c|}
\hline ام آرآى مغزى & باربارا & كشتى & جيتا & تصوير \\
\hline rI/A4Q & $r q / \cdots \wedge$ & $r q / .1 r$ & TE/TMI & الكموريتمم12] K-SVD] \\
\hline rT/A৭g & $r \cdot|8| \Delta$ & $r \cdot / F T \Delta$ & rV/RTA & روش تطبيق فضا |27| \\
\hline gr/r/r & $r r / \cdot \Lambda \Delta$ & $r \mid r \Delta l$ & rA/Frr & روش بيشنهيانى \\
\hline
\end{tabular}


(جدول - Y): مقادير نسبت بيك سيحَال به نوفه حاصل از حذف نوفه تصوير با بهكاركيرى روش يادَيرى وازهنامه مبتنى بر تطبيق فضا و

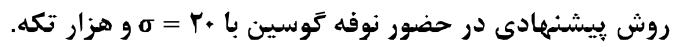

(Table-2): PSNR values of different image denoising methods using dictionary learning technique in the presence of Gaussian

\begin{tabular}{|c|c|c|c|c|}
\hline ام آرآى مغزى & باربارا & كشتى & جيتا & تصوير ـ \\
\hline$r \mid / F+Q$ & $r q / \cdots 1$ & $r 9 / \cdot 1 r$ & YG/YYI & الغوريته K-SVD [12] \\
\hline ru/va. & rq/994 & rq/.99 & 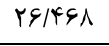 & روش تطبيق فضا [27] \\
\hline Tr/DGA & $r+/ 1 \Delta \lambda$ & rq/VAl & TG/QVT & روث پيشنهيانى \\
\hline
\end{tabular}
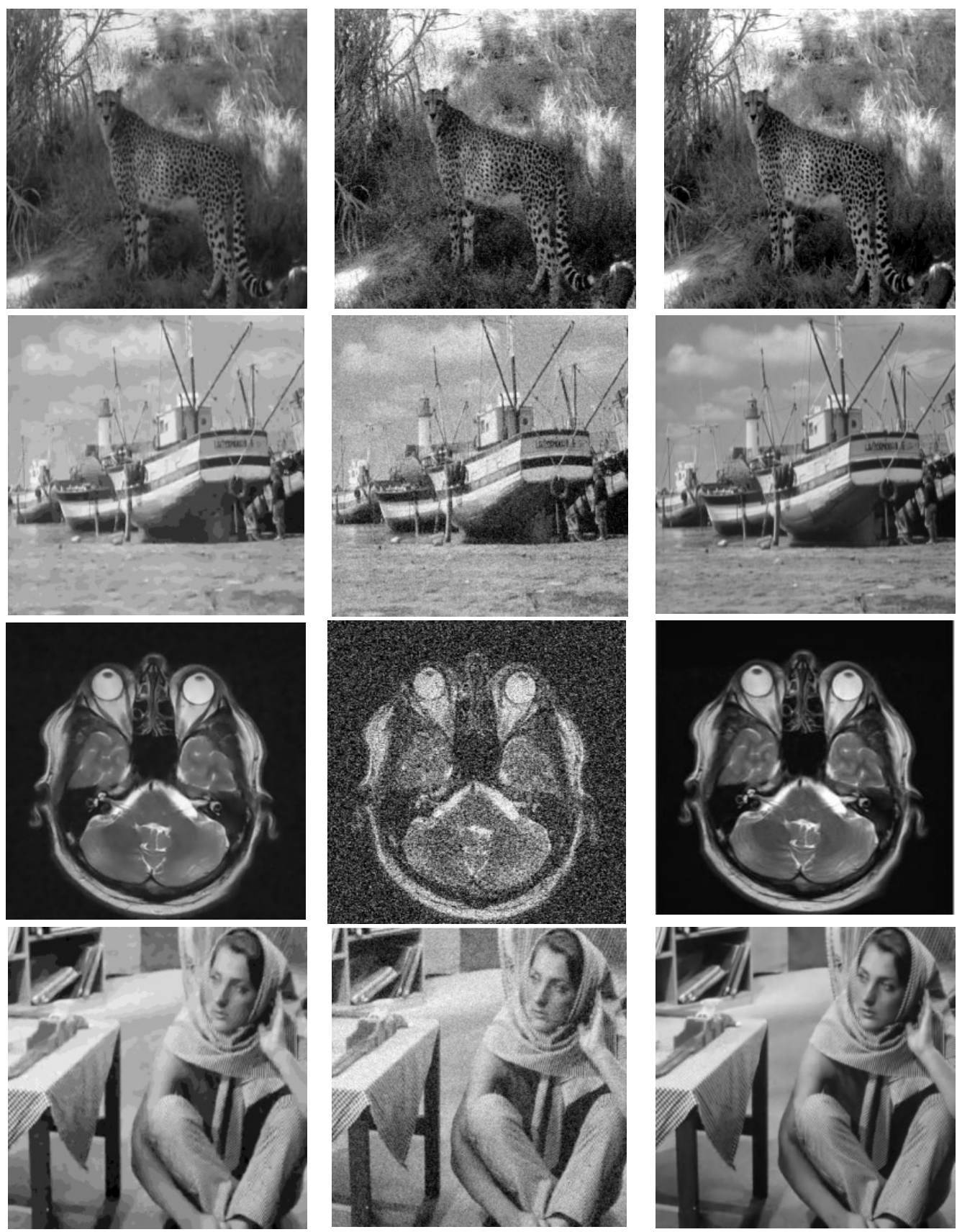

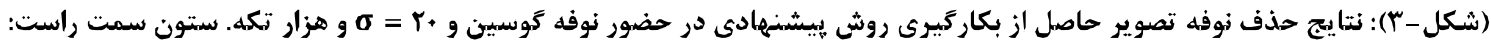

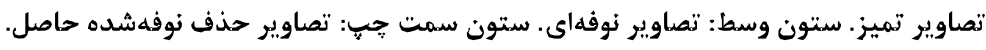

(Figure-3): Results of image denoising based on the proposed algorithm in the presence of Gaussian noise with $\sigma=20$ for 1000 patches of noisy image. Right column: Clean images. Middle column: Noisy images. Left column: Denoised image. 
ساير تصاوير (به جز ام آر آى) است و اين بدان علت است كه

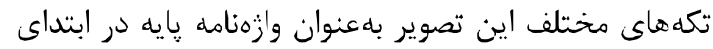
آموزش وزهنامه D

بنابراين تكهماى تصوير ورودى در هنغام بازنمايى

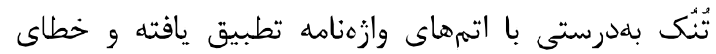

$$
\text { تقريب كمترى حاصل ميىشود. }
$$
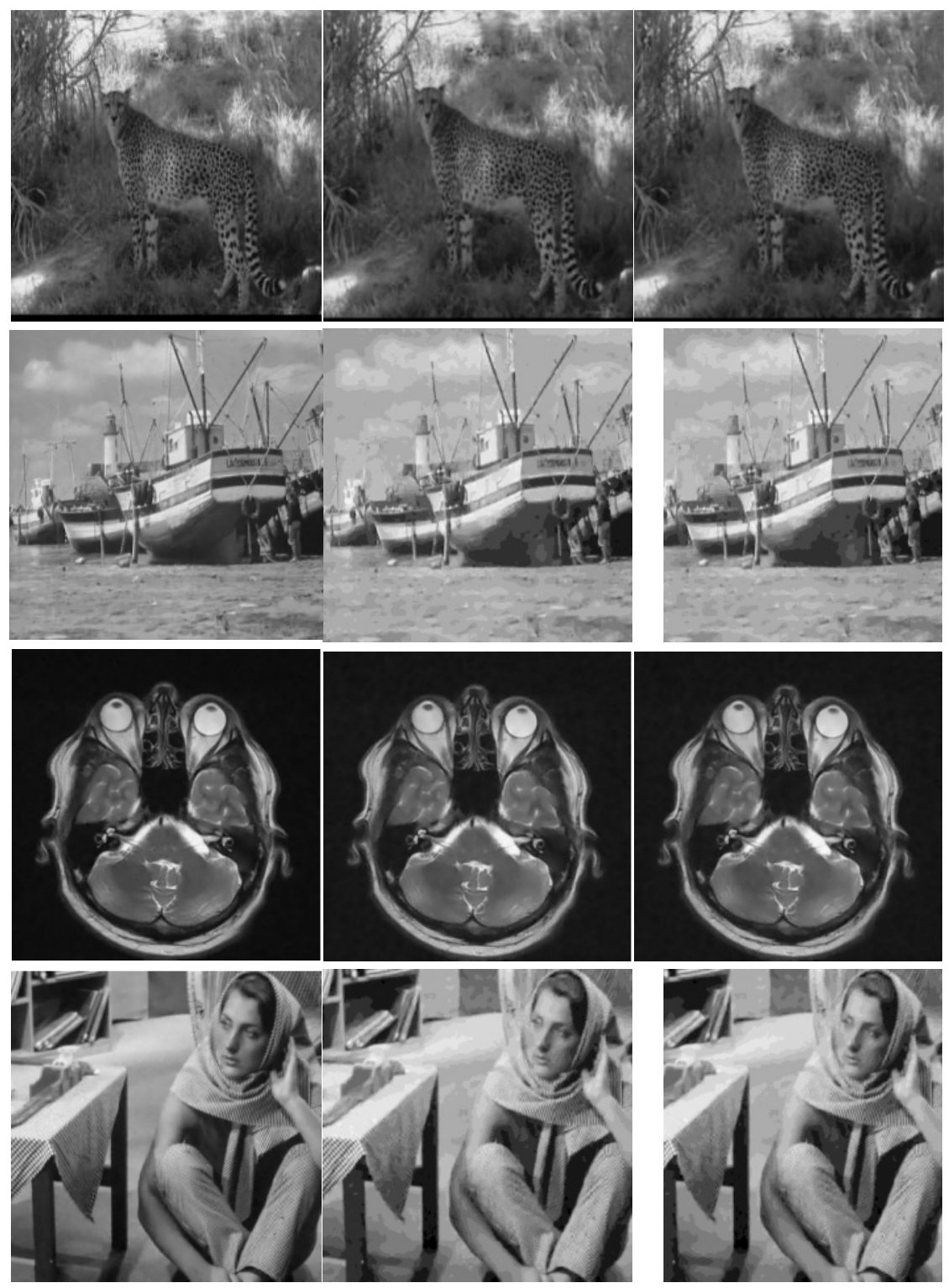

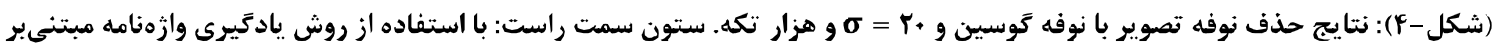

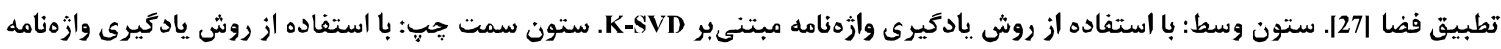
مبتنى بر روش وييشنهادى.

(Figure-4): Results of image denoising in the presence of Gaussian noise with $\sigma=20$ for 1000 patches. Right column: The dictionary learning based on domain adaptation [27]. Middle column: The denoising algorithm based on K-SVD dictionary learning. Left column: The proposed method. 
مختلف درنظركرفته شده از تصوير نوفهاى و تطبيق وازمنامه براساس آن بهمنظور مدل كردن نوفه محيط آزمايش براى روش بيشنهادى در شكل (Q) آورده شده است؛ همجنين

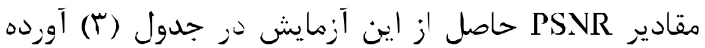
شده است. همانطوركه مشخص است هر جه تعداد تكهها افزايش يابد، داده بيشترى بهمنظور تطبيق فضا در دسترس خواهد بود و حذف نوفه بهصورت مطلوبترى انجام مىشون. همجنين مقادير PSNR حاصل از اين آزمايش در جدول (r) آورده شده كه بيان
همجنين PSNR حاصل از حذف نوفه تصوير ام آر آى

مغزى نيز بالا است ازآنجايى كه زمينه اين تصوير تيره بوده و آموزش وازمنامه براى جنين تصاويرى با تعداد تكههاى

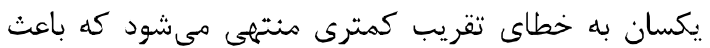

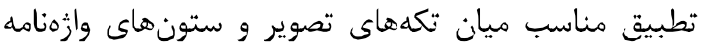

$$
\text { مىشود. }
$$

اين امر موجب مىشود كه بازنمايى مطلوبى براى

تكههاى مختلف تصوير كه تغييرات كمى دارند، حاصل شود. نتايج حاصل از حذف نوفه تصوير براساس تعداد تكدهاي

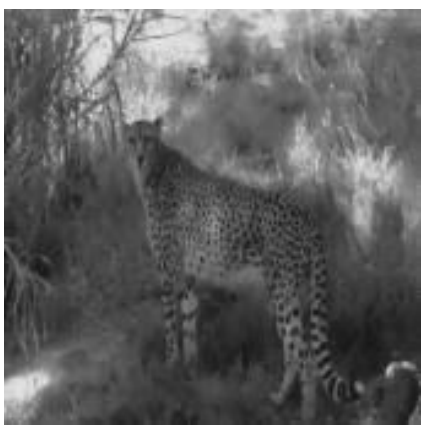

(ج)

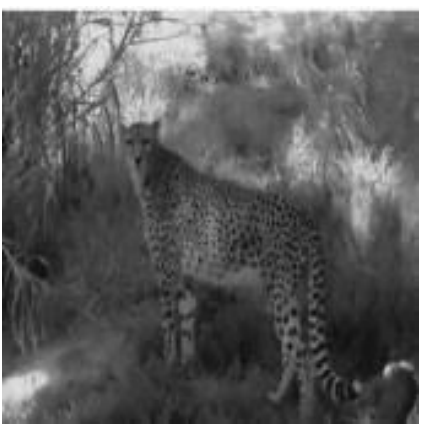

(ى)

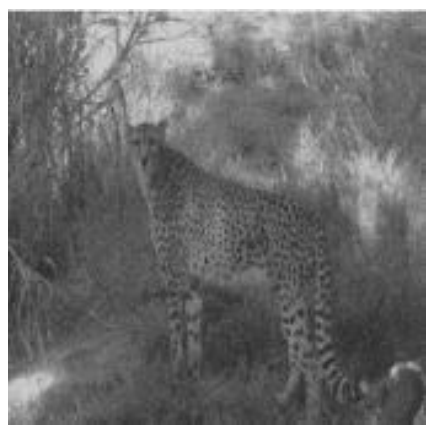

(ب)

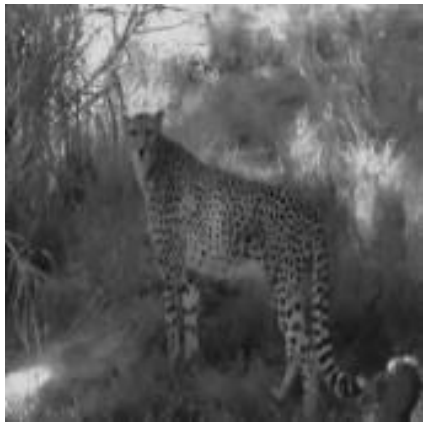

(0)
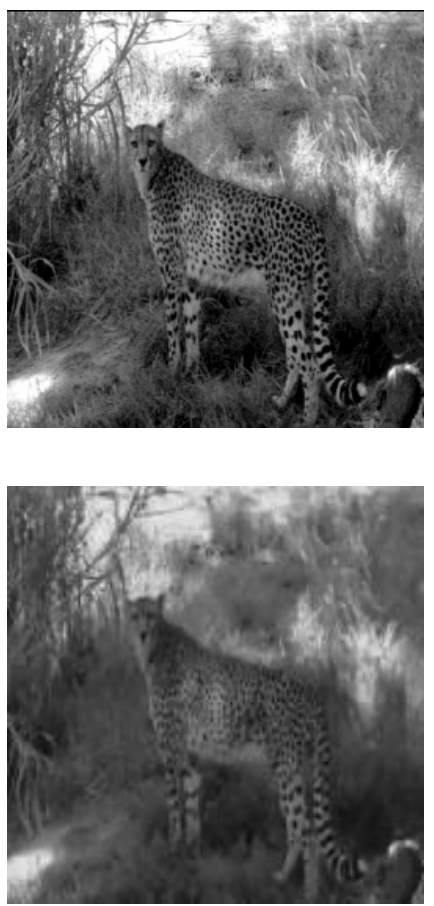

(د)

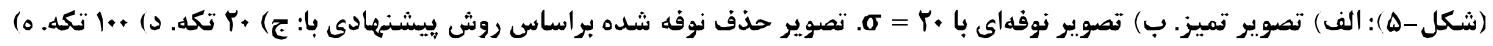

. 9 ...

(Figure-5): a) Clean image. b) Noisy image with $\sigma=20$. The denoised images based on the proposed method with different numbers of patches: e) 20 patches. d) 100 patches. e) 600 patches. I) 1000 patches.

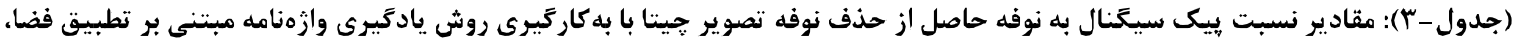

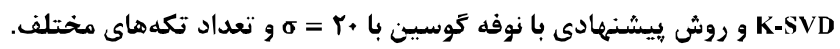

(Table-3): PSNR values of dictionary-based image denoising approaches for chectah image in the presence of Gaussian noise with $\sigma=20$ for different numbers of patches.

\begin{tabular}{|c|c|c|c|c|}
\hline $1 \ldots$ & $4 .+$ & $1 .$. & r. & $\begin{array}{c}\text { تعداه تكدهاى انتخابى از } \\
\text { تصوير نوفهمىى }\end{array}$ \\
\hline TE/TrI & TE/YTI & TE/YTI & TE/THI & الكَوريتم K-SVD [12] \\
\hline TVIVTA & re/vqr & rG/\&V. & rE/F\&A & روش تطبيق فضا [27] \\
\hline rA/Frt & rVIArq & $r V / \cdot V I$ & re/arr & روش ييشنيهادى \\
\hline
\end{tabular}


(جدول - (F): مقادير نسبت بيكى سيخنال به نوفه حاصل از حذف نوفه تصوير جيتا با بهكاركيرى روش يادكيرى وازمنامه مبتنى بر تطبيق فضا،

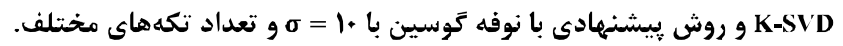

(Table-4): PSNR values of dictionary-based image denoising approaches for chectah image in the presence of Gaussian noise with $\sigma=10$

\begin{tabular}{|c|c|c|c|c|}
\hline $1 \cdots$ & 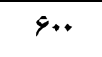 & $1 \cdots$ & $r$. & تعداد تكههاي انتخابى از تصوير نوفهى ـ \\
\hline$r \cdot / 4+s$ & $r \cdot / 4+s$ & $r \cdot / 4+s$ & $r \cdot / F F s$ & الكوريتم K-SVD | \\
\hline rI/ASV & $r / 4 \cdot q$ & $r M / . r \Delta$ & $r \cdot / \wedge 9 r$ & روش تطبيق فضا [27] \\
\hline$r r / F \Delta r$ & rI/989 & $M I / \Delta \xi V$ & $r 1 / 11 r$ & روش پيششنهادى \\
\hline
\end{tabular}

تُنْك Larc، قيد همدوسى براى تضمين حداقل شباهت ميان

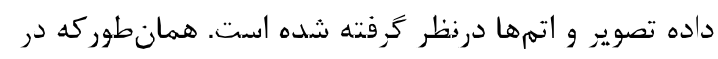

در شكل (ع) زمايشى از اتمهاى يادگيرىشده

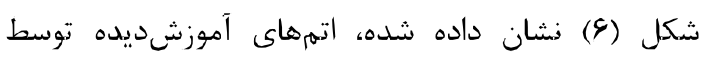

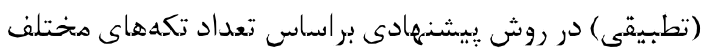

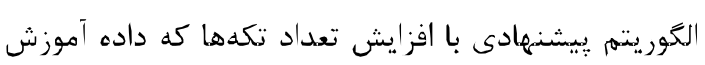

انتخابشده از تصوير نوفهاى آورده شده است. قابل مشاهده بردي

را تشكيل مى دهند، شباهت بيشترى به محتواى تصوير بيدا

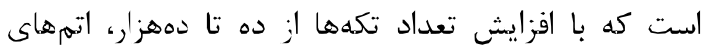

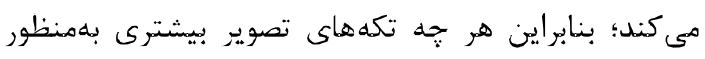

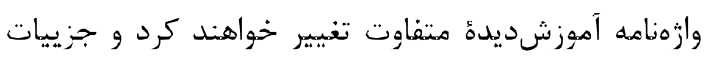

انجام روال آهوزش از هاده ورودى استخراج شود، اتمهها

بيشترى را از ساختار تصوير بازنمايى هى كنند.

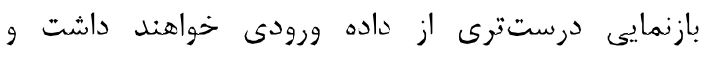

بايد توجه داشت كه اتهمهاى آهوزشديده براساس هر

همانطور كه در نتايج شبيهسازىها زشان داده شده، نتايج

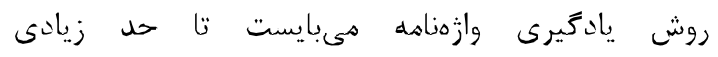

بهترى در حذف زوفه بهدست مى آيد.

بازمايى كننده هحتواى داده تصوير ورودى باشند. در روش ييشنهادى زيز بهعلت بهكارگيرى روش كد بزارى باززهايى

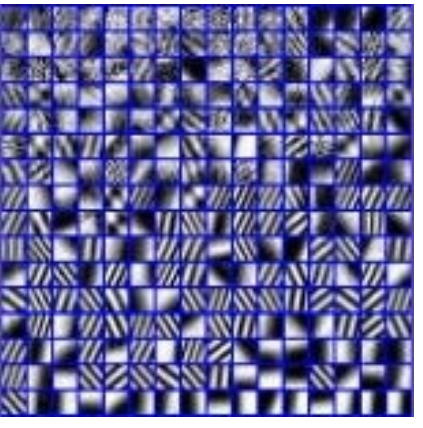

(ج)

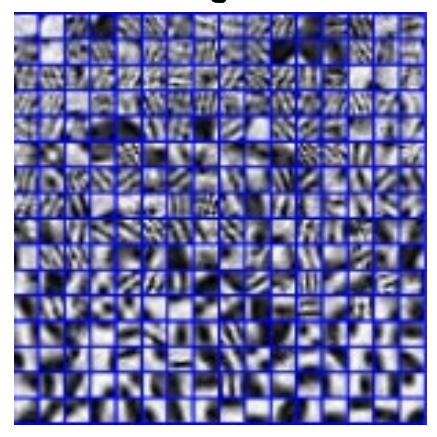

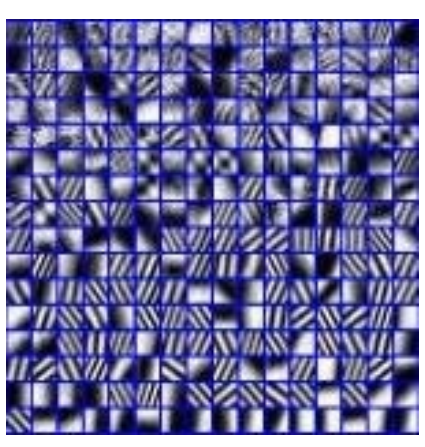

(ب)

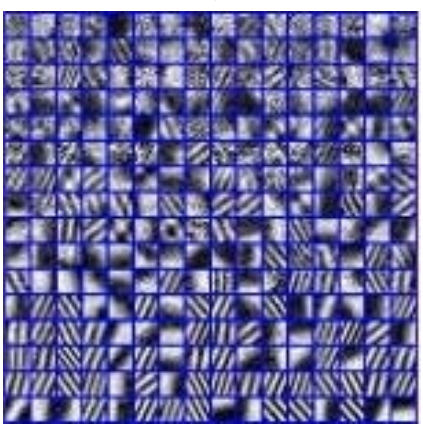

(o)

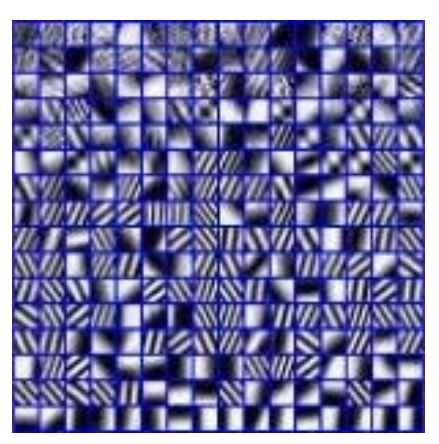

(الف)

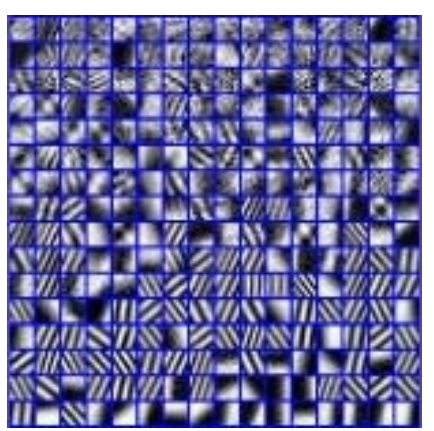

(د)

(شكل-و): زمايشى از اتمهاى تطبيق يافته براساس تعداد تكههاى مختلف انتخابشده از تصوير زوفهاى ورودى در روش پيشنهادى بهازاى:

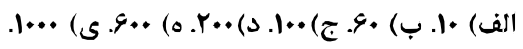

(Figure-6): Plot of the updated atoms according to the different number of patches selected from input noisy image using the proposed method for: a) 10 patches. b) 60 patches. c) 100 patches. d) 200 patches. e) 600 patches. f) 1000 patches. 
يادگيرى وازمنامه مبتنى بر آناليز مؤلفههاي اساسى، يادكيرى

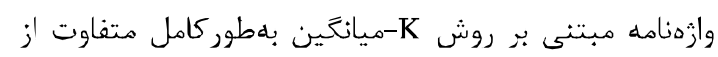
محتواى تصوير ورودى است كه مىتواند بيان كر اين مسأله باشد كه اين اتمها نمى توانند بهدرستى هحتواى ناده وده تصوير

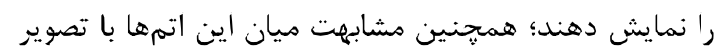

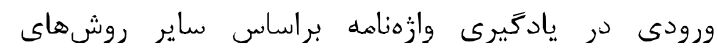
مقايسهشده مانند به كاركيرى فضاى بايه و بهخصوص روش بيشنهادى بهطور كامل مشهرون
در شكل ش نيز اتمهاى آموزشديده توسط

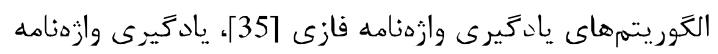

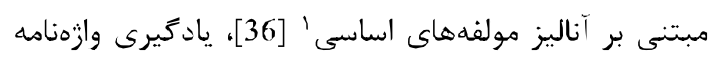

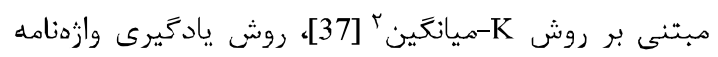

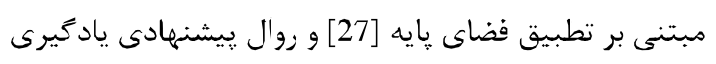

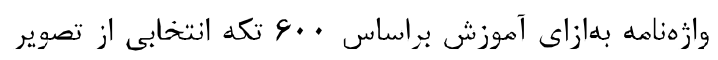
نوفهاى نشان داده شده است.

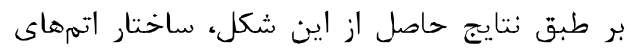

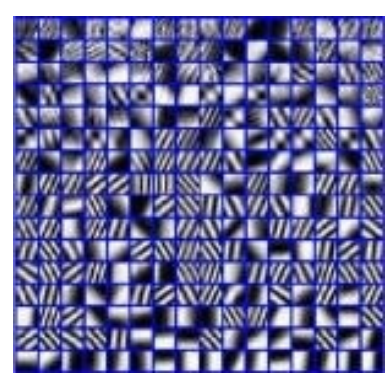

(ج)

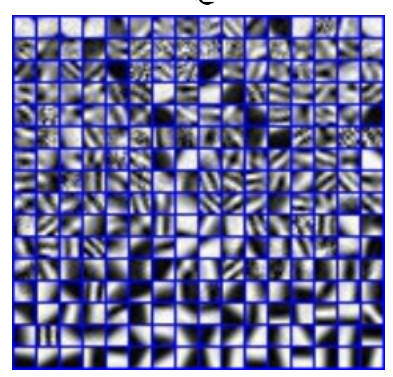

(ى)

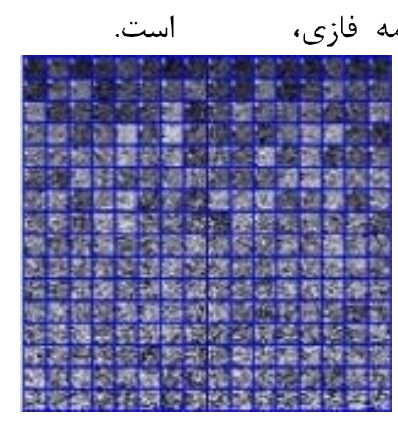

(ب)

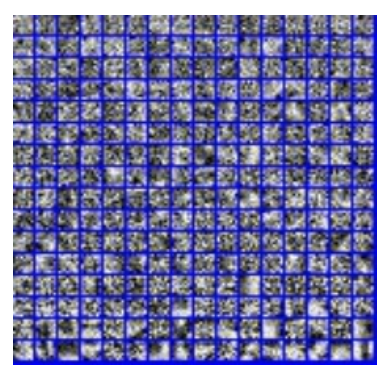

(o)

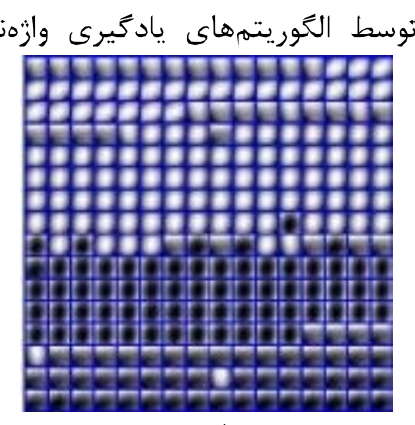

(الف)

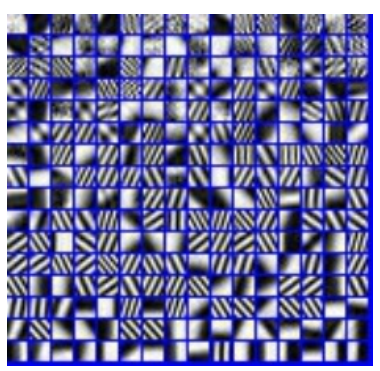

(د)

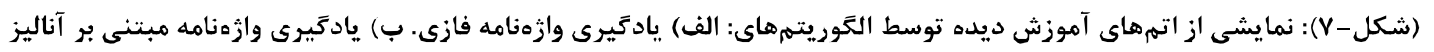

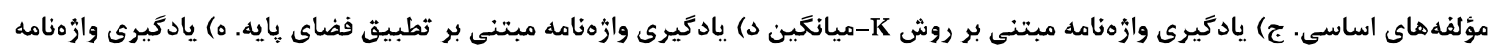

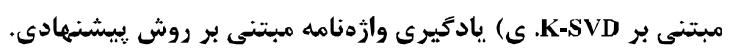

(Figure-7): Plot of learned atoms using different algorithms: a) Fuzzy dictionary learning. b) Dictionary learning based on principle component analysis. c) Dictionary learning based on K-means. d) Dictionary learning based on the adaptation learning algorithm |27|. e) Dictionary learning based on K-SVD. f)The proposed method.

كمترين مقدر نرخ همدوسى متقابل ميان اتم-داده و

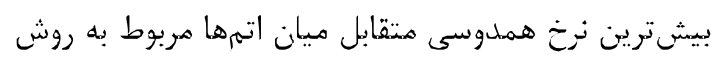

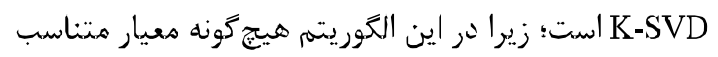

$$
\text { براى بـينه كردن نرخ همدوسى تعبيه نشده است. }
$$

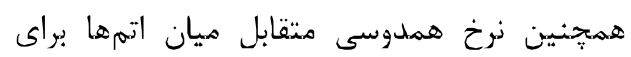

الكوريتم مبتنى بر تكنيك تطبيق فضا نيز هقدر زيادى دارد و اين هسأله نيز به اين دليل است كه در روش ارائهشده براساس اين روش هعيار همدوسى در نظر كرفته نشده است؛ اما روش بِيشنهادى با تكيه بر ترمهاى مختلف در نظركرفته

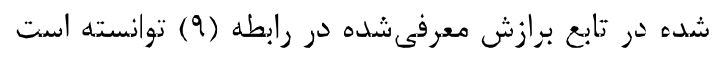

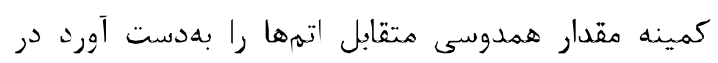

بامنظور بررسى يارامتر همدوسى متقابل ميان اتمها

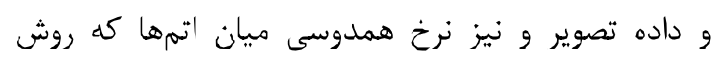
ييشنهادى بهترتيب براساس بيشينهسازى و كمينهسازى اين

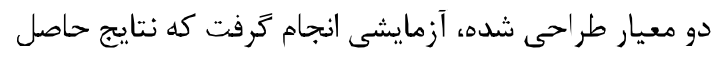

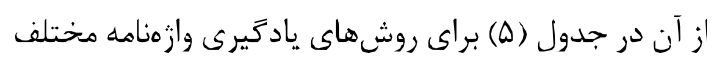

$$
\text { آورده شده است. }
$$

نتايج حاصل از اين جدول نشان مى نهد كه روش ييشنهادى با تكيه بر روال بهينهسازى ارائهشده بر مبناى يك إنى تابع برازش مناسب توانسته است به اين مههم دست ييدا كند.

${ }^{1}$ Principle component analysis(PCA)

${ }^{2} \mathrm{~K}$-means 
روش تطبيق فضا مورد بررسى قرار گرفت. معيار همدوسى

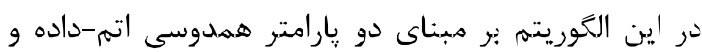
همدوسى متقابل ميان اتمها تعريف شده است. بيشينه كردن تن ين "بارامتر همدوسى اتم-داده در اين مقاله به كمك الكوريتهم

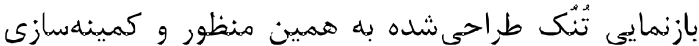
نرخ ههدوسى متقابل ميان اتمها براساس تابع برازش مناسب

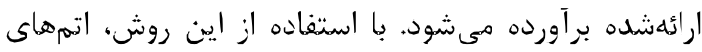

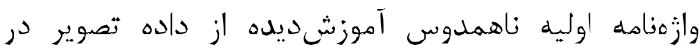
دسترس، براساس داده نوفه دحيط بر طبق روش تطبيق فضا

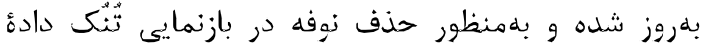

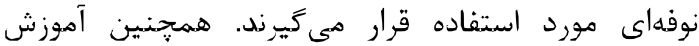

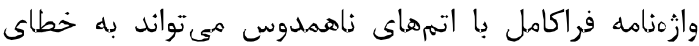
تقريب كوجکكى منتهى شود؛ زيرا در بازنمايى هر تكه تصوير، اتمهاى مستقل از هم نقش بيشترى خواهند داشت و فضاى دانه را به بهترين زحو يوشش مى دهند. به كار گيرى اين روال

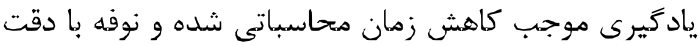
بيشترى از تصوير حذف مىشود. زتايج شبيهسازىهاى مونى

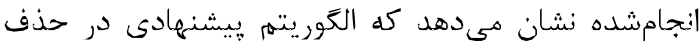
نوفه كوسين به نتايج مناسب ترى نسبت به الحوريتم پإيه در

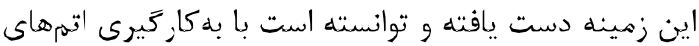
زاهمدوس، ساختار دادهٔ ورودى را به گونة مناسبى بازنمايى

\section{6- References}

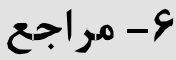

[1] H. Naimi, A. B. H. Adamou-Mitiche, L. Mitiche, "Medical image denoising using dual tree complex thresholding wavelet transform and Wiener filter", Journal of King Saud UniversityComputer and Information Sciences, vol: 27, no.1, pp. 40-45, 2015.

[2| A. Teodoro, M. Almeida, M. Figueiredo, "Singleframe image denoising and inpainting using Gaussian mixtures", International Conference on Pattern Recognition Applications and Methods (ICPRAM), pp. 283-288, 2015.

[3] S. Beckouche, J. L. Starck, and J. Fadili, "Astronomical image denoising using dictionary learning", $\Lambda$ stronomy \& $\Lambda$ strophysics $556, \Lambda 132$, 2013.

[4|Y. Zhu, C. Huang, "An improved median filtering algorithm for image noise reduction", Physics Procedia, no. 25, pp. 609-616, 2012.

[5] Y. L. You, M. Kaveh., "Fourth order partial differential equations for noise removal?", IEEE Trans. Image Processing, vol. 9, no. 10, pp. 1723 1730,2000
شرايطى كه بيشينه مقدار همدوسى ميان اتم-داده برآوزده

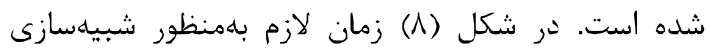
الخوريتهم مرجع [27] و روش زبيشنهادى برحسب تعداد تكههاى كرفتهشده از تصوير نوفهاى ورودى بهمنظور تطبيق وازٔهنامه اوليه با شرايط نوفهاى محيط نشان داده شده است. بديهى است كه هر جهه تعداد اين تكهها زيادتر باشد تا بتوان تطبيق با دقت بالاتر ميان وازمنامه اوليه و تكههاى نوفهاى

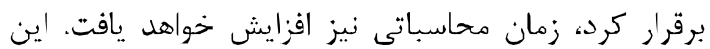

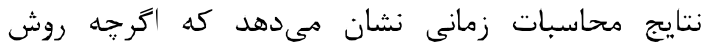
ييشنهادى به اندك زمان بيشترى نسبت به روش تطبيق فضاى يايه بهمنظور آموزش وازمنامه جهت حذف نوفه تصوير نياز مارد، اما با توجه به نتايج حاصل از شكلها و و جداول اين بخش به خطاى تقريب كمترى دست بيدا مى كند.

(جدول - ه) : مقدار نرخ همدوسى متقابل ميان اتم -داده و نرخ

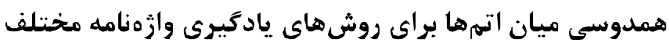

(Table-5): Atom-data coherence value and coherence value between atoms for different dictionary-based image

\begin{tabular}{|c|c|c|}
\hline \multicolumn{3}{|c|}{ denoising methods } \\
\hline نرخ همدوسى اتمهان & ميان متقابل همدوسى & روش به كارَّفته شده \\
\hline .199 & $\cdot / 4 T$ & روش K-SVD \\
\hline .101 &.$/ 48$ & روش تطبيق فضا [27] \\
\hline.$/ F r$ & $\cdot \mid \Delta \lambda$ & روش بيشنيهاثى \\
\hline
\end{tabular}

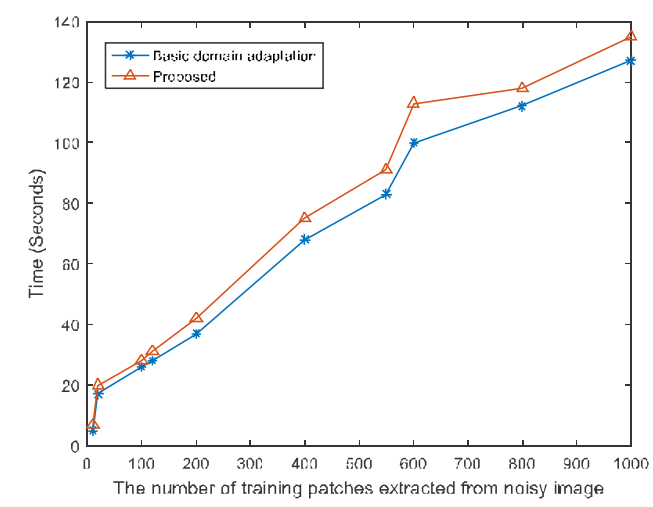

(شكل-1) : زمايش زمان اجراى الكوريتهم ٍِايه تطبيق فضا [27] و

روش بيجشنهادى برحسب تعداد تكه هاى اختصاص يافته از

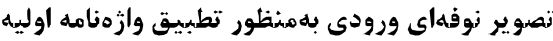

(Figure-8): Plot of computation time using dictionary learning based on domain adaptation technique [27] and the proposed method for different number of patches selected from input noisy image to update dictionary atoms

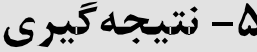

در اين مقاله يك الكوريتم جديد بهمنظور كاهش نوفه سيگنال تصوير براساس يادگيرى وازمنامه ناهمدوس مبتننىبر 
In Proceedings of the International Conference on Image Processing (ICIP), Brussels, Belgium, pp. 11 -14, 2011.

[17] X. Lu, H. Yuan, P. Yan, Y. Yuan, L. Li, X. Li, "Image denoising via improved sparse coding", Proceedings of the British Machine Vision Conference, pp. 74-81, 2011.

[18] J. Wang, J. F., Cai, Y. Shi, B. Yin, "Incoherent dictionary learning for sparse representation based image denoising", IEEE international Conference on Image Processsing. Piscataway, NJ: IEEE, pp. 4582-4586, 2014.

[19] T. Tong, J. Caballero, K. Bhatia, D. Rueckert, "Dictionary learning for medical image denoising, reconstruction, and segmentation", Machine Learning and Medical Imaging, pp. 153-181, 2016.

¡20] M. Karimipoor, V. Abolghasemi, S. Ferdowsi, " $\Lambda$ n Efficient Image Denoising $\Lambda$ pproach Based on Dictionary Learning", International Journal of Mathematics and Computational Science, vol. 2, no. 1, , pp. 1-7, 2016.

[21] G. Davis, S. Mallat, Z. Zhang, "Adaptive timefrequency decompositions", Optical-Engineering, vol. 33, pp. 218-391, 1994.

[22] A. Agarwal, A. Anandkumar, P. Jain, P. Netrapalli, R. Tandon, "Learning sparsely used overcomplete dictionaries", JMLR: Workshop and Conference Proceedings, vol. 35, pp. 1-15, 2014.

[23] H. Lee, A. Battle, R. Raina, A. Y. Ng, "Efficient sparse coding algorithms", Advances in Neural Information Processing Systems, 2006.

[24] J. Portilla, L. Mancera, "L0-based sparse approximation: Two alternative methods and some applications", Proceedings of the 16th IEEE international conference on Image processing, pp. 3865-3868, 2009

[25] K. Engan, S. O. Aase, J. H. Hakon-Husoy, "Method of optimal directions for frame design", IEEE International Conference on Acoustics, Speech, and Signal Processing., vol. 5 , pp. 2443-2446, 1999.

[26] K. Delgado, J. F. Murray, B. D. Rao, K. Engan, T. Lee, T. J. Sejnowski, "Dictionary learning algorithms for sparse representation", Neural Computation., vol. 15, no. 2, pp. 349-396, 2003.

[27] G. Chen, C. Xiong, J. J. Corso, "Dictionary transfer for image denoising via domain adaptation," In Proceedings of ILEL International Conference on Image Processing, 2012.

[28] S. Mavaddaty, S. M. $\Lambda$ hadi, S. Scyedin, " $\Lambda$ novel speech enhancement method by learnable sparse and low-rank decomposition and domain

$$
\begin{aligned}
& \text { [F] مهلى زاده همت آبادى، امير، حسينى فاطمى، } \\
& \text { محمدرضا، "حذف نوفه تصاوير با استفاده از الكوريتم } \\
& \text { بهبود يافته تطبيت بلوك و فيلتر سه بعدى"، اولين }
\end{aligned}
$$

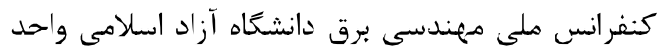

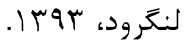

[6] A. Mehdizadeh, M. Hosseinifatemi, "Image denoising based on modified adapted block and 3D filter", $1^{\text {st }}$ Conference on electrical engineering (ICEE2015), Langaroud, 2015.

[7] C. IIuang, Y. Zhu, "New Morphological Filtering Algorithm for Image Noise Reduction", Second International Congress on Image and Signal Processing, 2009, pp. 1-6.

|8| R. G. Baraniuk, "Compressive Sensing," IEEE Signal Processing Magazine, pp. 118-121, 2007.

[9] D. Donoho, "Compressed sensing," IEEE Trans. Inform. Theory, vol. 52, no. 4, pp. 1289-1306, 2006.

[10] T. Gan, W. Lu, "Image denoising using multiscale sparse representation", School of Electrical \& Electronic Engineering, Nanyang Technological University, Singapore, Proceedings of IEEE 17th International Conference on Image Processing, pp. 1165-1168, 2010.

¡11] P. Chatterjee, P. Milanfar, "Image denoising using locally learned dictionaries", Department of Electrical Engineering, University of California, Santa Cruz, CA 95064, USA, 2009.

[12] M. Aharon, M. Elad, A. Bruckstein, "K-SVD: $\Lambda \mathrm{n}$ algorithm for designing overcomplete dictionaries for sparse representation", IEEE Trans. Signal Process, vol. 54, no. 11, pp. 4311-4322, 2006.

[13] Z. Fen, X. Kai, “A novel image denoising method based on DCT basis and sparse representation", Cross Strait Quad-Regional Radio Science and Wireless Technology Conference, College of information \&mechanical enginecring Beijing Institute of Graphic Communication, pp.1307-1310, 2011.

[14] J. Mairal, M. Elad, G. Sapiro, "Sparse learned representations for image restoration", In Proc. of the 4th World Conf. of the Int. Assoc. for Statistical Computing (IASC), Yokohama, Japan, 2008.

$\lceil 15\rceil$ S. Li, L. Fang, H. Yin, "An efficient dictionary learning algorithm and its application to 3-D medical image denoising", IELE transactions on biomedical engineering, vol. 59, no. 2, pp. 417-427, 2012.

[16] W. S. Dong, X. Li, L. Zhang, G. M. Shi, "Sparsity-based Image Denoising via Dictionary Learning and Structural Clus-tering", 


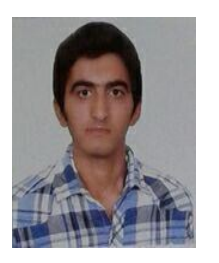

رضا مظفرى تحصيلات خود را در

مقطع كارشناسى و كارشناسى ارشد در مر

رشته مهيندسى برق -الكترونيك بهترتيب در سال |وس| در مؤسسه

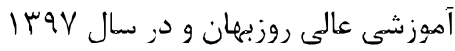
در مؤسسه آموزش عالى علوم و فناورى آريان به بايايان

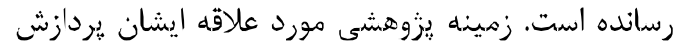

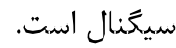

نشانى رايانامه ايشان عبارت است ازن: rezamozaffari3@gmail.com

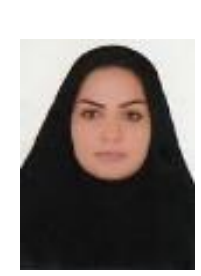

سميرا مودّتى هدارك كارشناسى و

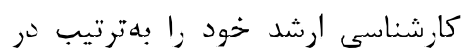

سالهاى

هازندران در رشته همندسى برق-

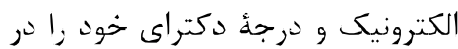

سال هوس| |ز دانشكاه صنعتى امير كبير در رشته هرهندسى

برق - الكترونيك دريافت كرد. وى هم اكنون استاديار گروه

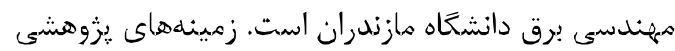

مورد علاقه ايشان عبارت است ازئ يردازش سيخنال كفتار،

يردازش سيحنال تصوير، بهينهسازى و هوش مصنوعى. مورد.

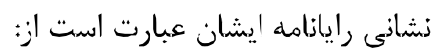

s.mavaddati@umz.ac.ir adaptation", Speech Communication, vol. 76, pp. 42-60, 2016.

[29] S. Chen, S.A. Billings, W. Luo. "Orthogonal least squares methods and their application to non-linear system identication", International Journal of Control., vol. 50, pp.1873-1896, 1989.

[30] D. Barchiesi, M. D. Plumbley, "Learning incoherent dictionaries for sparse approximation using iterative projections and rotations", IEEE Transactions on Signal Processing, vol. 61, no. 8, pp. 2055-2065, 2013.

[1 [ب] ميرجليلى، عليرضا، ابوطالبى، وحيد، صادقى، محمد

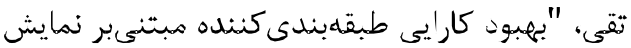

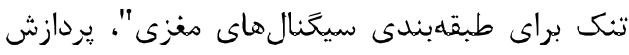

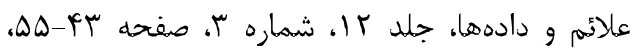

.1494

[31] A. Mirjalili, V. Abootalebi, M. T. Sadeghi, "Improving the performance of sparse representation-based classifier for EEG classification", JSDP, vol. 12, no. 3, pp. 43-55, 2015.

[32] C. D. Sigg, T. Dikk, J. M. Buhmann, "Speech enhancement using generative dictionary learning", IEEE Transactions on Audio, Speech and Language Processing, vol. 20, no. 6, pp.1698-1712, 2012.

[33] B. Efron, T. Hastie, I. Johnstone, R. Tibshirani, "Least angle regression", Ann. Stat., vol. 32, pp. 407-499, 2004.

[34] D. Liu and J. Nocedal, "On the limited memory BFGS method for large scale optimization", Math. Program, vol. 45, pp. 503-528, 1989.

[35] X. Song, Z. Liu, “ $\Lambda$ Fuzzy adaptive K-SVD dictionary algorithm for face recognition", Proceedings of the 2nd International Conference on Computer Science and Electronics Engineering (ICCSEE), pp. 2164-2168, 2013.

[36] G. Jenatton, F. Bach. "Structured sparse principal component analysis", Technical report, pp. 366-373, 2009.

[37] M. Elad and M. Aharon, "Image denoising via sparse and redundant representations over learncd dictionarics", IEEE Trans. on Image Processing, vol. 15, no. 12, pp. 3736-3745, 2006. 
